\title{
Validation of the particle finite element method (PFEM) for simulation of free surface flows
}

\author{
A. Larese, R. Rossi, E. Oñate and S.R. Idelsohn \\ International Center for Numerical Methods in Engineering (CIMNE), \\ Universidad Politécnica de Cataluña, Barcelona, Spain
}

\section{Validation of the PFEM}

\begin{abstract}
Purpose - The purpose of this paper is to evaluate the possibilities of the particle finite element method for simulation of free surface flows.

Design/methodology/approach - A numerical simulation of a number of examples for which experimental data are available is performed. The simulations are run using the same scale as the experiment in order to minimize errors due to scale effects. Some examples are chosen from the civil engineering field: a study of the flow over a flip bucket is analyzed for both 2D and 3D models, and the flow under a planar sluice gate is studied in 2D. Other examples, such as a 2D and 3D "dam break" with an obstacle are taken from the smooth particle hydrodynamics literature.

Findings - Different scenarios are simulated by changing the boundary conditions for reproducing flows with the desired characteristics. Different mesh sizes are considered for evaluating their influence on the final solution.

Originality/value - Details of the input data for all the examples studied are given. The aim is to identify benchmark problems for future comparisons between different numerical approaches for free surface flows.
\end{abstract}

Keywords Flow, Simulation, Fluid dynamics, Finite element analysis

Paper type Research paper

\section{Introduction}

The availability of sufficient computer power, together with the maturity of the tools for CFD analysis, opens the way to the simulation of flow problems of increasing complexity. Between the many practical applications, the simulation of free-surface flows represents a particularly interesting problem. The challenge is in this case connected both to the inherent difficulty in the simulation of a highly unsteady flow and to the rapid variation of the shape of the "fluid body." This second feature is particularly demanding for the fluid simulation as it requires the constant (and automatic) redefinition of the boundary conditions.

Different methods have been devised over the years to deal with this challenge.

A first category of algorithms is based on the idea of tracking the evolution of a free surface defined with the help of a smooth distance function (level set) (Osher and Fedkiw, 2001), or of a scalar value representing the quantity of fluid in a given area.

This work has been partially funded by the PROFIT 2005 program of the Spanish Ministerio de Educación y Ciencia (MEC) through the project STRUCT-LNG (file number CIT-370300-2005-16) and by the Beatriu de Pinos program of the Generalidad de Cataluña. Support of the SEDUREC project of the Consolider + INGENIO 2010 program of the MEC is also acknowledged.

Received 18 April 2007 Revised 2 January 2008 Accepted 10 January 2008

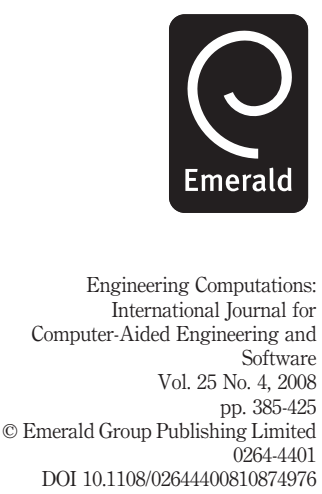


EC

25,4

\section{6}

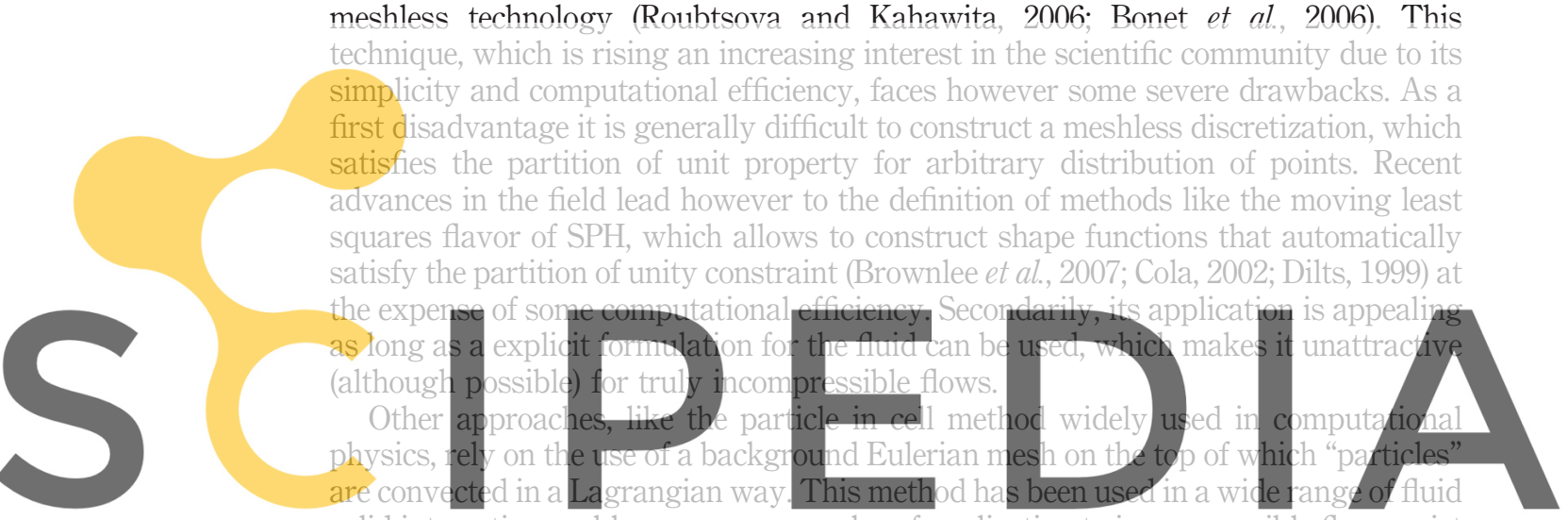

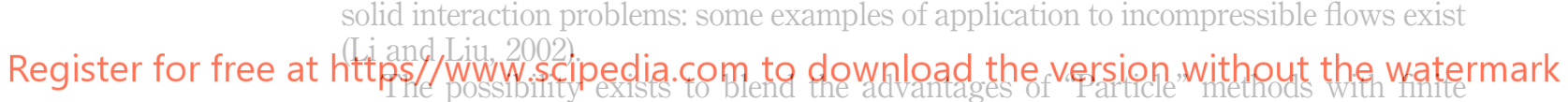

This is the basis of the volume of fluid (VOF) technique. This scalar function is convected according to the flow velocity field once a suitable discretization of the space is provided. This allows using existing Eulerian codes and this justifies the success of the VOF method in the CFD community. This formulation permits to deal naturally with separation (or reattachment) of parts of the fluid domain; nevertheless some concerns remain particularly on the imposition of the Dirichlet boundary conditions on the free surface. Even if all the advantages of Eulerian methods on fixed meshes can be retained, the VOF approach tends to introduce some diffusion in the position of sharp interfaces (see for examples Zalesak's circle benchmark (Osher and Fedkiw, 2003)).

An alternative formulation, known as smooth particle hydrodynamics (SPH) allows the Lagrangian simulation of a number of particles through the use of a simple meshless technolooy (Roubtsova and Kahawita, 2006: Bonet et al. 2006). This technique, which is rising an increasing interest in the scientific community due to its simplicity and computational efficiency, faces however some severe drawbacks. As a first disadvantage it is generally difficult to construct a meshless discretization, which satisfies the partition of unit property for arbitrary distribution of points. Recent advances in the field lead however to the definition of methods like the moving least squares flavor of SPH, which allows to construct shape functions that automatically satisfy the partition of unity constraint (Brownlee et al., 2007; Cola, 2002; Dilts, 1999) at achieves this resuit by convecting in a Lagrangian way the fluid "particies" while redefining at the beginning of each step a new mesh (Oñate $e t$ al., 2004; Idelsohn $e$ t al., 2006). This allows to reproduce very accurately the convection of the nodes and to impose the Dirichlet conditions in a natural way. Further, all of the convergence results can be inherited from the FE technique which guarantees the reliability of the computational predictions (Oñate et al., 2004).

The PFEM treats the mesh nodes in the fluid domain as particles which can freely move and even separate from the main fluid domain representing, for instance, the effect of water drops. A FE mesh connects the nodes defining the discretized domain where the governing equations are solved in the standard FEM fashion. The PFEM is the natural evolution of recent work of the authors for the solution of FSI problems using Lagrangian FE and meshless methods (Aubry et al., 2005; Idelsohn et al., 2006, 2004; Oñate et al., 2004).

An obvious advantage of the Lagrangian formulation is that the convective terms disappear from the fluid equations. The difficulty is however transferred to the problem of adequately (and efficiently) moving the mesh nodes. We use an innovative mesh regeneration procedure blending elements of different shapes using an extended Delaunay tesselation (Idelsohn et al., 2006, 2004). 
The need to properly treat the incompressibility condition in the fluid still remains in the Lagrangian formulation. The use of standard FE interpolations may lead to a volumetric locking defect unless some precautions are taken (Donea and Huerta, 2003; Zienkiewicz et al., 2005). In our work, the stabilization via a finite calculus (FIC) procedure has been chosen (Oñate, 2000). Applications of the FIC method for incompressible flow analysis using linear triangles and tetrahedra are reported in Oñate et al. (2004), Oñate and Idelsohn (1998) and Oñate and García (2001).

The objective of this work is to show the ability of the PFEM for reproducing real experiments comparing experimental values with numerical results. Different examples of civil engineering situation are considered. The flux over a flip bucket, the under seal flow, the dam break with an obstacle are the experiments that are described and reproduced with the PFEM. The position of the free surface and the velocity and pressure fields are the parameters chosen for the experimental-numerical comparisons. The influence of the mesh size and of the viscosity effects are also investigated in some detail.

\section{Overview of the PFEM}

Let us consider a domain containing both fluid and solid subdomains. The moving particles interact with the solid boundaries thereby inducing the deformation of the solid which in turn affec In the PFEM, both the Lagrangian formulation

assumed to be known in th domains are sough EMI is used to solve
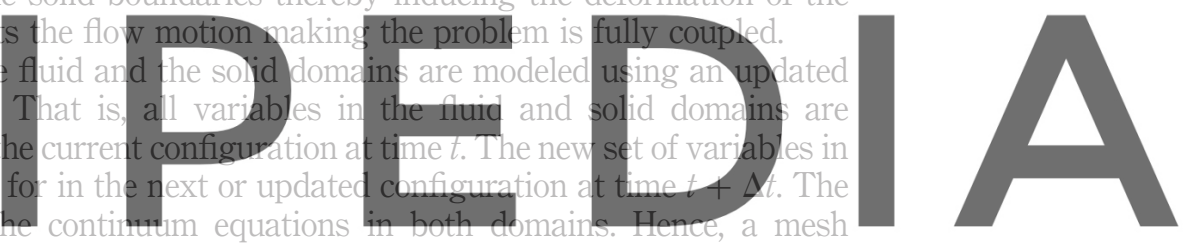

discretizing these domains must be generated in order to solve the governing equations

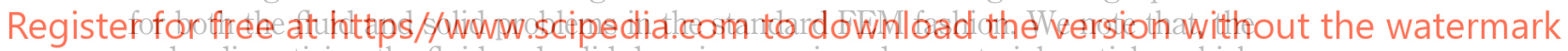
nodes discretizing the fluid and solid domains are viewed as material particles which motion is tracked during the transient solution. This is useful to model the separation of fluid particles from the main fluid domain and to follow their subsequent motion as individual particles with a known density, an initial acceleration and velocity and subject to gravity forces.

It is important to note that each particle is a material point characterized by the density of the solid or fluid domain to which it belongs. The mass of a given domain is obtained by integrating the density at the different material points over the domain.

The quality of the numerical solution depends on the discretization chosen as in the standard FEM. Adaptive mesh refinement techniques can be used to improve the solution in zones where large motions of the fluid or the structure occur.

\subsection{Basic steps of the PFEM}

For clarity purposes we will define the collection or cloud of nodes $(C)$ pertaining to the fluid and solid domains, the volume $(V)$ defining the analysis domain for the fluid and the solid and the mesh $(M)$ discretizing both domains.

A typical solution with the PFEM involves the following steps:

(1) The starting point at each time step is the cloud of points in the fluid and solid domains. For instance, ${ }^{n} \mathrm{C}$ denotes the cloud at time $t=t_{n}$ (Figure 1). 
$\mathrm{EC}$

25,4

\section{8}
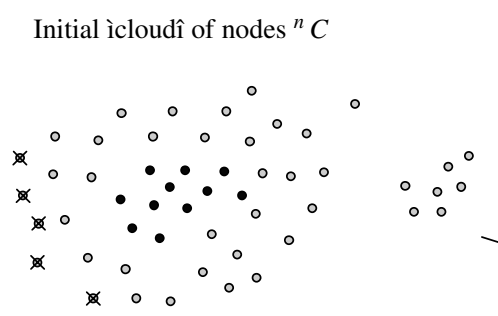
- Fluid node
- Solid node
Fixed boundary node
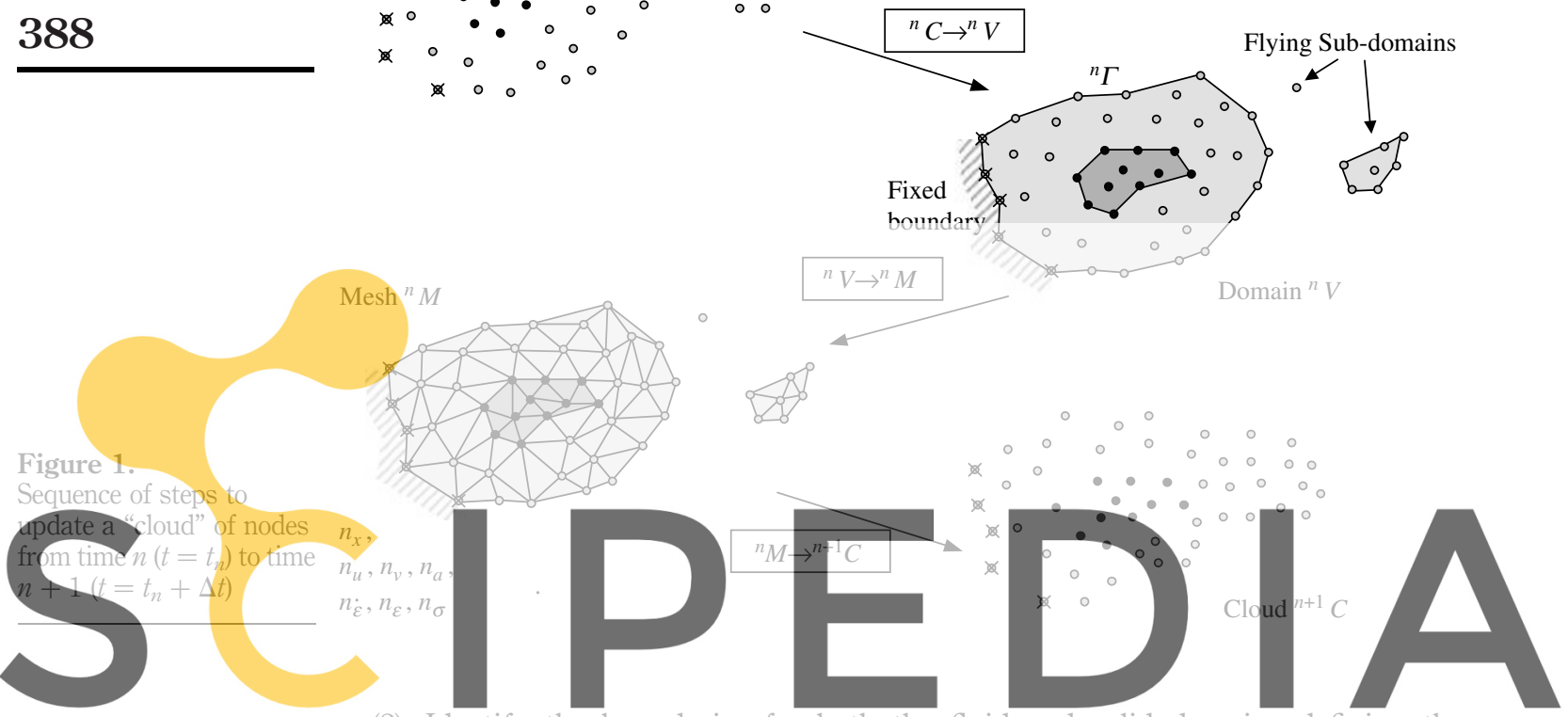

(2) Identify the boundaries for both the fluid and solid domains defining the

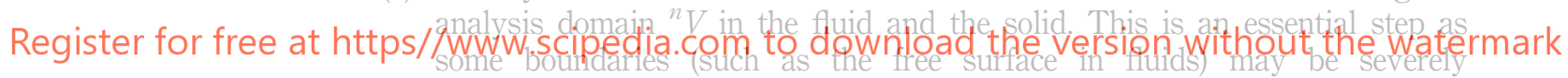
distorted during the solution process including separation and re-entering of nodes. The Aipha shape method (Edeisbruner and Viucke, 1994) is used for the boundary definition.

(3) Discretize the fluid and solid domains with a FE mesh ${ }^{n} M$. In our work, we use an innovative mesh generation scheme based on the extended Delaunay tessellation (Idelsohn et al., 2006, 2004; Oñate and Idelsohn, 1998).

(4) Solve the coupled Lagrangian equations of motion for the fluid and the solid domains. Compute the relevant state variables in both domains at the next (updated) configuration for $t+\Delta t$ : velocities, pressure and viscous stresses in the fluid and displacements, stresses and strains in the solid.

(5) Move the mesh nodes to a new position ${ }^{n+1} C$ where $n+1$ denotes the time $t_{n}+\Delta t$, in terms of the time increment size. This step is typically a consequence of the solution process of Step 4 .

(6) Go back to Step 1 and repeat the solution process for the next time step.

Figure 2 shows a typical example of a PFEM solution in 2D. The pictures correspond to the analysis of the problem of breakage of a water column (Oñate et al., 2004, 2006). Figure 2(a) shows the initial grid of three-noded triangles discretizing the fluid domain 


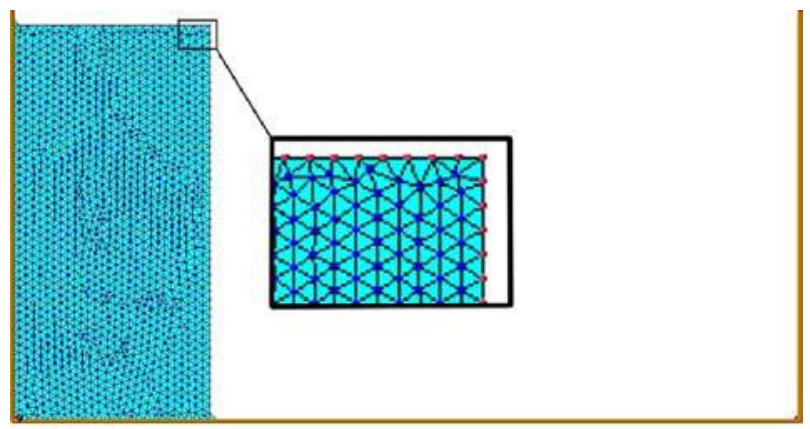

Validation of the PFEM

(a)

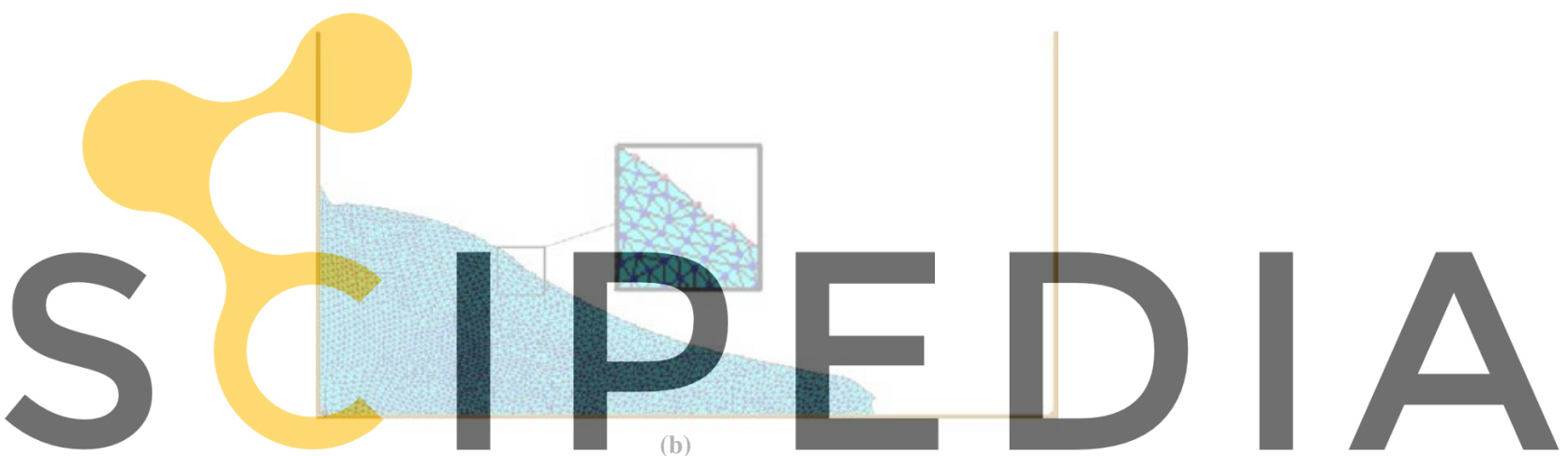

Register for free at https//www.scipedia.com to download the version without the watermark

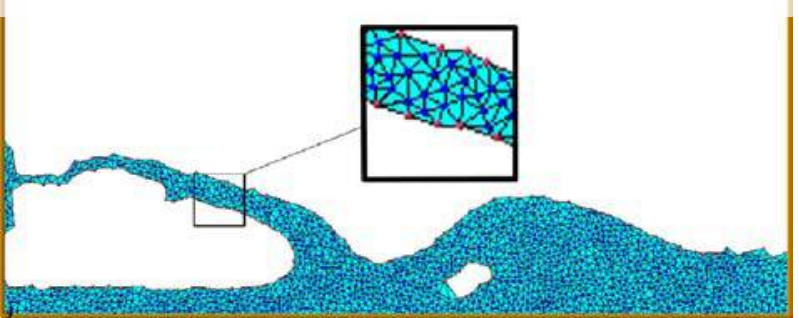

(c)

Note: Figures show the evolution of the FE mesh discetizing the water domain at different instances
Figure 2.

Breakage of a water column analyzed with the

PFEM

and the solid walls. Figure 2(a) and (c) show the mesh for the solution at two later times. Details of the PFEM can be find in Oñate et al. (2004), Idelsohn et al. (2006, 2004) and Aubry et al. (2005).

The following sections describe a suite of benchmark tests chosen for the experimental validation of the PFEM. 
EC

25,4

390

\section{Flip bucket}

Flip buckets are energy dissipators used at the end of ski jump spillway of large dams; their purpose is to throw the water well clear off the dam. The jet of a ski jump spillway leaves horizontally whereas the jet of a flip bucket is deflected upwards to induce disintegration in the air particles. Particular care should be taken in the construction of the dissipation pool, which is the impact zone. Moreover, the spray produced can cause damage to the surroundings and may adversely affect nearby electrical installations.

Some examples of existing flip buckets are here shown in Figure 3(a) and (b).

\subsection{Experimental setting}

Both $2 \mathrm{D}$ and $3 \mathrm{D}$ models are considered in order to reproduce the experimental setup developed by Juon and Hager (2000) at the Zurich University. The original aim of their investigation was to propose a simple theory for the behavior of a flux over flip buckets. This implied the derivations of fitting curves from the experimental data which are taken for comparison with the PFEM results (Figure 4).

The experiments were conducted in a rectangular $7 \mathrm{~m}$ long channel; its base was $0.499 \mathrm{~m}$ and its height was $0.7 \mathrm{~m}$. It was divided into two different zones:
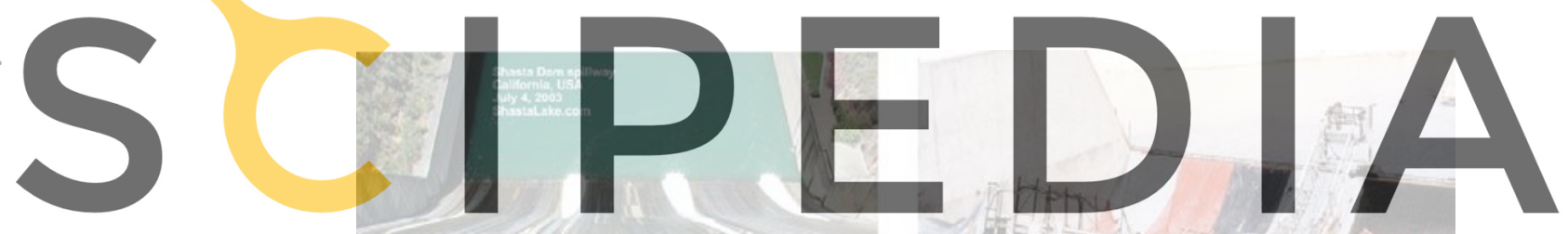

Register for free at https//www.scipedia.com to download the version without the watermark

Figure 3.

Examples of existing dams with flip buckets
Figure 4.

Flip bucket. Experimental set-up taken from

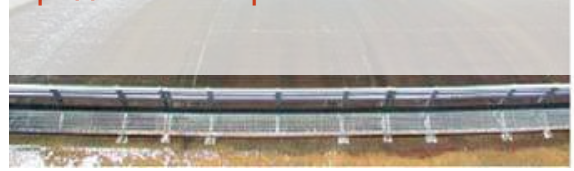

(a) Shasta Dam Spillway, California

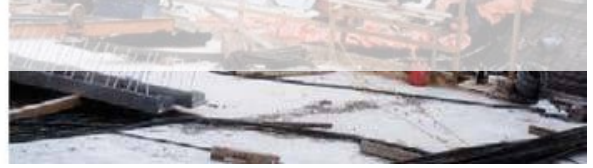

(b) St.Mary's Dam, Alberta

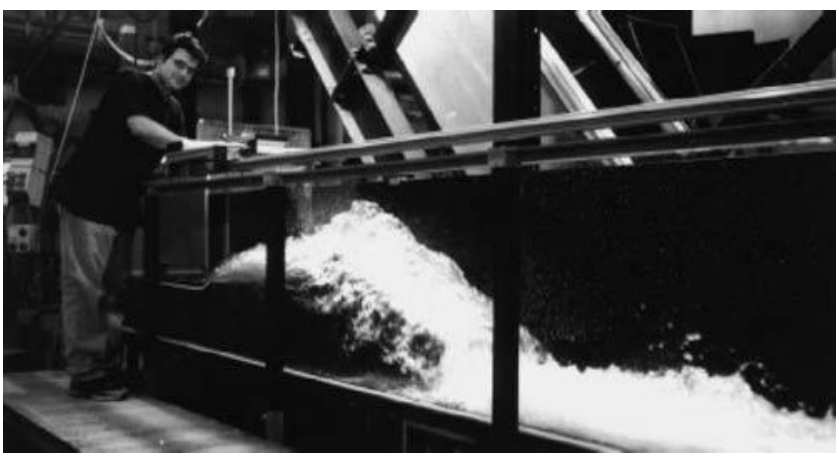


(1) the upper part includes a $1 \mathrm{~m}$ long approach channel and the invert; and

(2) the downstream part, thus conserving the width of the channel, simulating the dissipation pool.

\section{Validation of the PFEM}

The discharge was controlled by a jet-box that was regulated to obtain the designed flow velocity and flow depth $h_{0}$; in our work we have taken a constant value of $h_{0}=0.05 \mathrm{~m} . R$ varies from 0.20 to $0.25 \mathrm{~m}$ and the invert angle was $\beta=30^{\circ}$. The upper

391 point of the flip bucket was placed at $w+h_{s}$ above the downstream channel with $h_{s}=0.25 \mathrm{~m}$ and $w=(1-\cos \beta) R$ (bucket elevation) as shown in Figures 4 and 5 . The free surface profile and of the upper and lower nappe profiles for the jet were identified using a point gauge to \pm 0.5 and $\pm 0.1 \mathrm{~mm}$, respectively.

The second part of the experiment included a 3D analysis: a deflector was placed in the channel. It was regulated starting from $\varphi=0^{\circ}$ (the 2D case) until $\varphi=30^{\circ}$. The effect of the deflector is the creation of a shock wave.

\subsection{Flip bucket experimental results}

Juon and Hager (2000) obtained a theoretical description of flow over flip buckets by the extrapolation of fitting functions starting from experimental data. These functions are the starting point for the validation tests. A brief overview follows of all the equations used in our work. More details on the experiment can be found in Juon and Hager (2000).

The gathering of experimental data starts from prescribing different inflon depths nd discharge values. In impos 7 .

On the base of Juon and Hager (2000) results, it is possible to trace a qualitative jet trajectory of the upper and lower nappe profile from the take-off point and of the

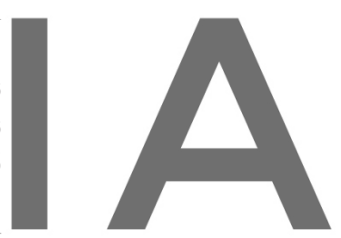

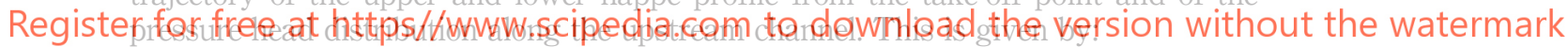

$$
z=z_{0}+\tan \alpha_{j} x-\frac{g x^{2}}{2 V_{j}^{2} \cos ^{2} \alpha_{j}} .
$$

The empirical data follow well the parabola of a mass point shown in equation (1) where $\alpha_{j}$ is the take-off angle, $V_{j}$ is the take-off velocity that can be considered equal to the velocity at the entry $V_{0}$ for flow conditions without scale effects (Juon and

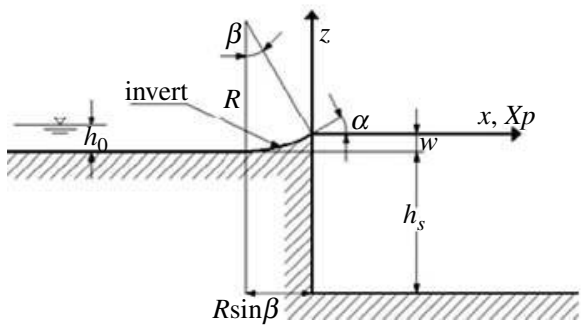

(a) Side

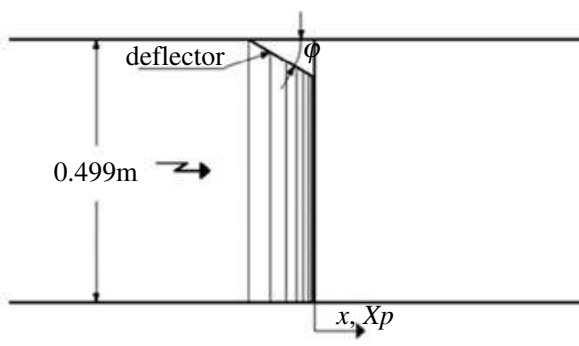

(b) Plane
Figure 5.

Flip bucket. Schematic representation of experimental set-up 
EC

25,4

\section{2}

Hager, 2000). This equation emanates from the classical equation of parabolic motion:

$$
z=z_{0}+\tan \alpha_{j} x-\frac{1}{2} g t^{2}
$$

where, the time is computed as:

$$
t=\frac{x}{V_{j} \cos \alpha_{j}}
$$

where, $V_{j} \cos \alpha_{j}$ is the steady velocity along the $x$ axis.

Figure 6 shows the comparison between experimental datain the upper and lower profile of the jet trajectory, obtained for different radiae $(R)$, inflow depth $\left(h_{0}\right)$, and Froude numbers $F r$ and the parabola of a mass point in non-dimensional terms. The theoretical equation is in this case:

$$
Z_{0}=\tan \alpha_{j} X-\frac{1}{2} \frac{X^{2}}{\cos ^{2} \alpha_{j}} ;
$$

where, $X=\left(x / h_{0} F r_{0}^{2}\right)$ and $Z_{0}=\left(z_{0}-h_{0}\right) /\left(z_{m}-h_{0}\right)$ (Figure 7).

An important detail is that the take-off angle $\alpha_{j}$ is significantly smaller than the

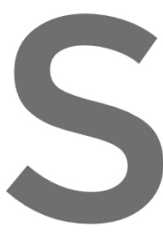

invert angle $\beta=$ :

the ratio between

Hager, 2005):

Register for free at https//www.scipsedia.çom to download

Figure 6.

Flip bucket.

Non-dimensional jet trajectory obtained as the average of experimental results taken from

Figure 7.

Flip bucket. Jet trajectory obtained as the average of experimental results

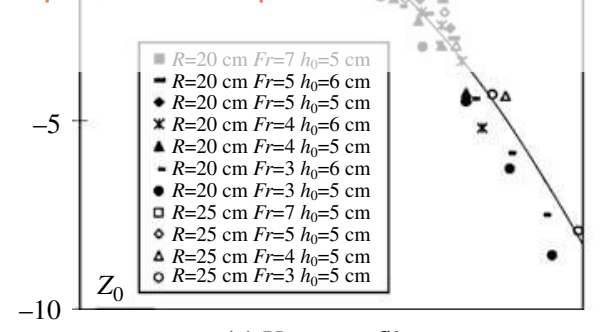

(a) Upper profile

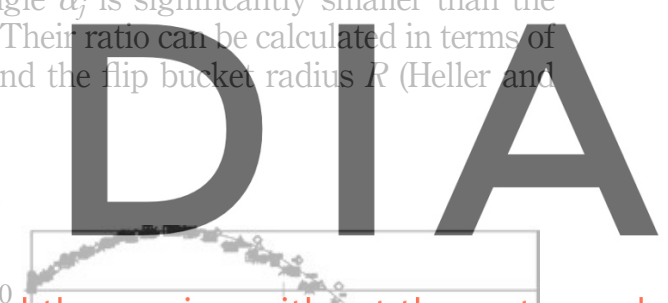

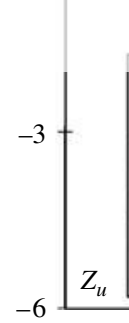

$-6$

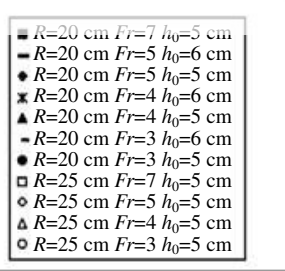

(b) Lower profile

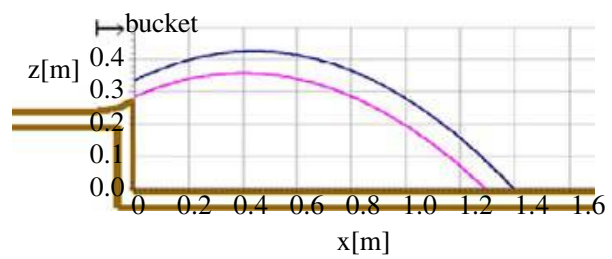

Source: Juon and Hager (2000) 


$$
\frac{\alpha_{0}}{\beta}\left(\frac{70^{0}}{\beta}\right)^{1 / 6}=\frac{1}{2}\left[1+\exp \left(-8\left(\frac{h_{0}}{R}\right)^{2}\right)\right] ; \quad \text { for } \quad 0 \leq\left(\frac{h_{0}}{R}\right) .
$$

\section{Validation of the PFEM}

The attention is focused on the pressure $\left(h_{P}\right)$ that develops along the approach channel and along the invert. Pressure has to be constant and equal to $h_{P}=h_{0}=0.05 \mathrm{~m}$, and it has to be equal to the sum of a static pressure head $\left(h_{0}\right)$ plus a dynamic pressure head on the flip bucket. The dynamic part has to be different than zero only in the invert. A normalized pressure parameter used for the experimental-numerical comparisons is defined as (Juon and Hager, 2000):

$$
H_{\mathrm{P}}=\frac{h_{\mathrm{P}}-h_{0}}{h_{\mathrm{PM}}-h_{0}}
$$

where, the abscissa origin, $x=0$, is located at the take-off point and $R \sin \beta$ is the flip-bucket length, $h_{\mathrm{PM}}$ is the maximum pressure head plotted along the normalized streamline coordinate $X_{P}=x / R \cdot \sin \beta$ (Figure 8). This head is calculated as $h_{\mathrm{PM}} / h_{0}=$ $\left(h_{0} / R\right) F_{0}^{2}$ assuming a potential vortex model. This assumption is correct if the bend number $B=\left(h_{0} / R\right)^{0.5} F_{0} \leq 1.5$. The evolution of the experimental pressure head $H_{\mathrm{P}}$ as reported in Juon and Hager (2000) is:
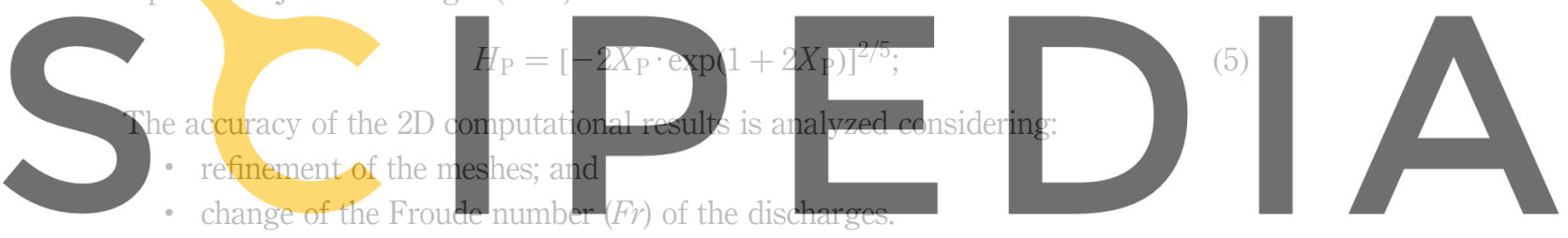

Registernfore fice an angle placed at the bucket entry. A shock wave is generated. The highest level the jet can achieve should be twice the maximum nappe height without deflector, and its planar contraction should occupy all the channel in function of the angle.

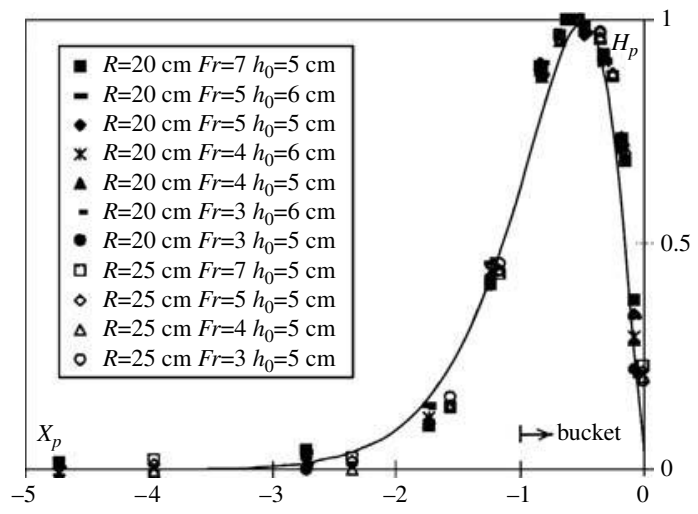

Note: $R=20-25 \mathrm{~cm} ; F r=3-7 ; h_{0}=5-6 \mathrm{~cm}$

Source: Juon and Hager (2000)
Figure 8.

Flip bucket. Non-dimensional pressure curve obtained as the average of experimental results 
EC

25,4

394

The shock-wave outline was described in Juon and Hager (2000) with the profile of a standard spillway (Figure 9):

$$
Z_{\mathrm{L}}=\frac{A\left(X_{\mathrm{L}}+B\right) \cdot \ln \left[A\left(X_{\mathrm{L}}+B\right)\right]}{C}-D
$$

For the specific case of $A=0.14, B=2.7, C=0.023$ and $D=16$ :

$$
\begin{gathered}
X_{\mathrm{L}}=\frac{x}{h_{0} F_{0}} ; \\
Z_{\mathrm{L}}=\frac{\left(z_{\mathrm{L}}-z_{\mathrm{LM}}\right)}{h_{0} \sin ^{3 / 8} \varphi} .
\end{gathered}
$$

With $Z_{\mathrm{LM}}$ being the maximum nappe elevation that, similarly as the maximum horizontal distance $x_{\mathrm{LM}}$, depends only on the Froude number as:

$$
\frac{x_{\mathrm{LM}}}{h_{0} F_{0}}=0.05 F_{0}^{2}
$$
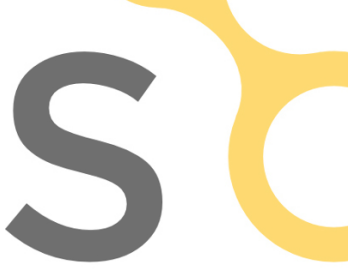

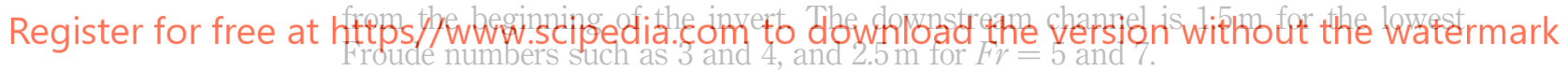

Figure 9.

Flip bucket. Shock-wave trajectory obtained as the average of experimental results

\section{Figure 10.}

Flip bucket. PFEM results for the development of the jet

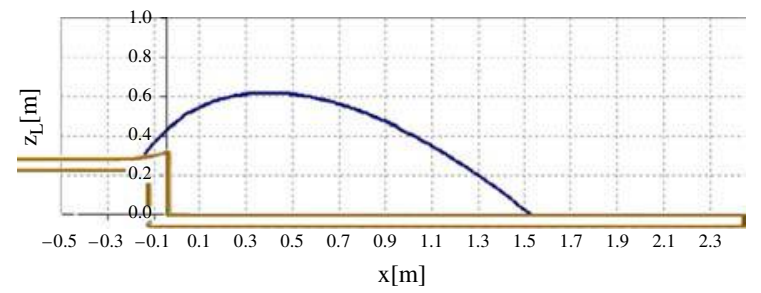

Source: Juon and Hager (2000)
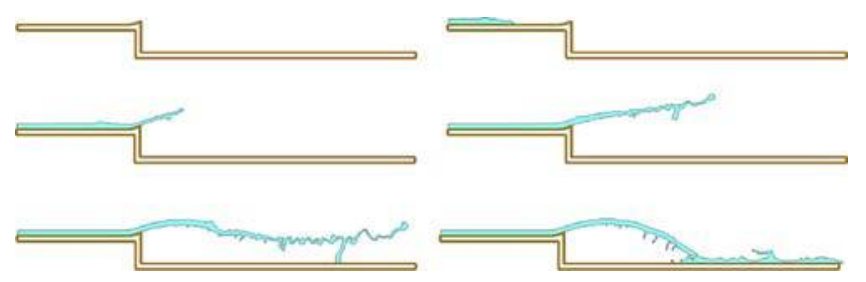
A no-slip boundary condition is imposed at the walls. Water is the considered fluid for all the analyzed experiments. Its physical characteristics are:

- density: $1,000 \mathrm{~kg} / \mathrm{m}^{3}$;

- dynamic viscosity: $10^{-3} \mathrm{~N} \mathrm{~s} / \mathrm{m}^{2}$; and

- inflow velocity: variable $x$-component in terms of $F r$ (Table I).

Basically, two different meshes were considered for each value of $F r$, while keeping constant the depth of the inflow discharge equal to $h_{0}=0.05 \mathrm{~m}$ and the flip bucket radius equal to $R=0.25 \mathrm{~m}$. The initial element size for the first mesh is $0.01 \mathrm{~m}$ while for the second one is $0.005 \mathrm{~m}$. The PFEM models initially have, respectively, 831 and 1,659 linear elements. A shorter model was sufficient in the case of the slowest discharges ( $F r=3$ and 4$)$ as the jet touched the channel after less than a meter. The initial meshes in this case have, respectively, 631 and 1,259 linear elements.

All the triangular elements are created at each time step to simulate the entry of the fluid; the number of the elements increase of some 100 percent in few seconds of simulations.

3.3.1 Jet trajectory. Few seconds of analysis are necessary to achieve a steady state. Pressure over the invert and jet trajectory are not influenced by the development of the downstream conditions.

As expected, the accuracy of the output jet trajectory improves when the mesh is refined (Figures 11-15).

\begin{tabular}{lrrc}
\hline Model & $F r$ & $Q(l / \mathrm{s})$ & $v_{\text {in }}(\mathrm{m} / \mathrm{s})$ \\
\hline A & 3 & 52.41 & 2.1 \\
B & 4 & 69.88 & 2.8 \\
C & 5 & 87.35 & 3.5 \\
D & 7 & 122.29 & 4.9
\end{tabular}

Table I.

Flip bucket. Discharge data for the four models
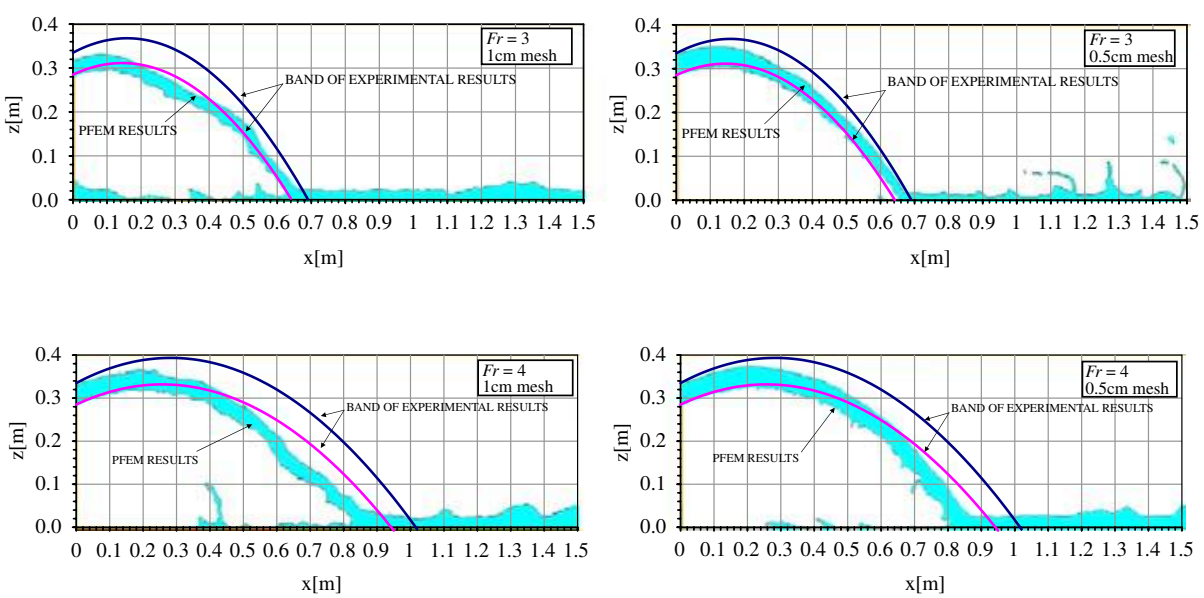

Validation of the PFEM

395 
EC

25,4

\section{6}

The accuracy of the PFEM results is also higher with the increasing for the velocity. This can be explained by the reduced importance of the viscosity effects which cannot be resolved on the coarse meshes used. The biggest discrepancy occurs for $F r=3$ and the $1 \mathrm{~cm}$ mesh as shown in Figure 16(b). Experimental results are quite different from the computational ones, once the steady state is reached. The flow seems not to have the energy to keep the jet active. The accuracy of PFEM results increases when using a finer element size. This is clearly seen in Figure 16(a) where results for the $0.5 \mathrm{~cm}$ mesh are shown (Table II).

3.3.2 Pressure results. Looking at the output of the bottom pressure distribution and comparing the PFEM results with the graphs interpolating the experimental data, the differences were not significant Figures 17-19. Along the approach channel, as already said, the pressure head $\left(H_{\mathrm{p}}\right)$ should be constant and equal to the depth of the flow.

Accuracy improves using a finer mesh, as expected. As for the analysis of trajectory, also in pressure case, the model with a discharge with $F r=3$ gave the less accurate results (Figure 17). Unfortunately, mesh refinement does not improve the solution. If the coarse mesh gives a lower level of pressure, the finer mesh overestimates the maximum pressure head by a 10 percent.

Better accuracy is achieved for a higher velocity both for the coarse and the fine meshes as shown in Figures 18 and 19. Smaller oscillations and increasing of accuracy can be noticed using a finer mesh for a fixed velocity.

Figure 13.

Flip bucket. $F r=5$. Comparison between PFEM results and the band of experimental values for the jet trajectory

Figure 14.

Flip bucket. $F r=7$. Comparison between PFEM results and the band of experimental values for the jet trajectory
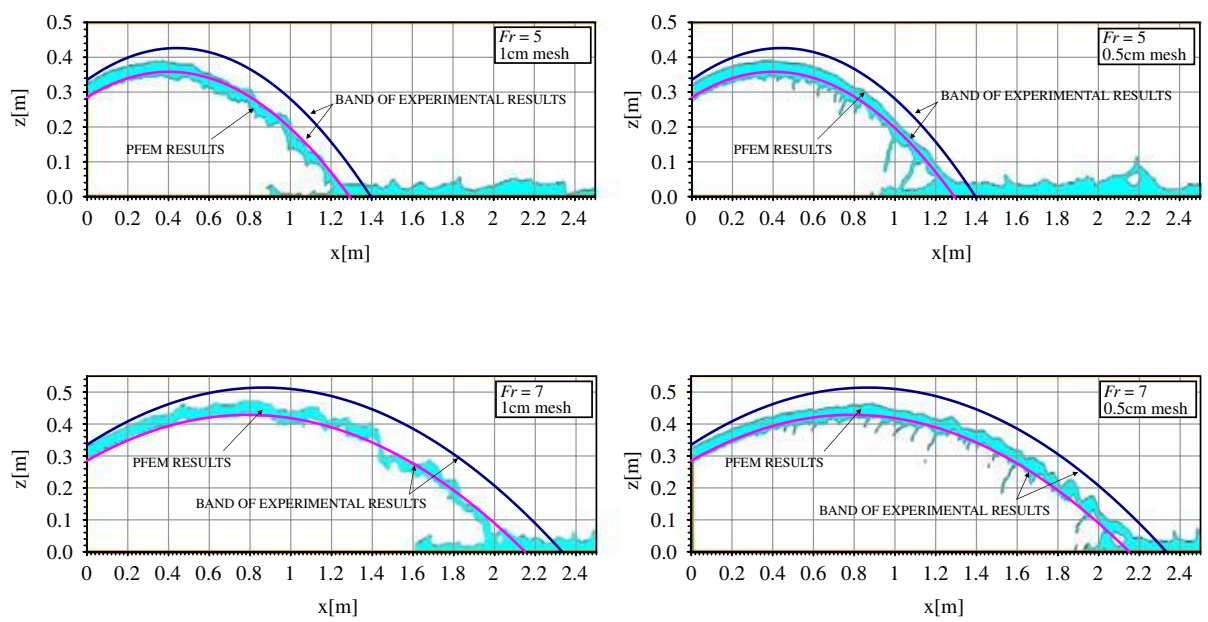

Figure 15.

Flip bucket flow.

Side view

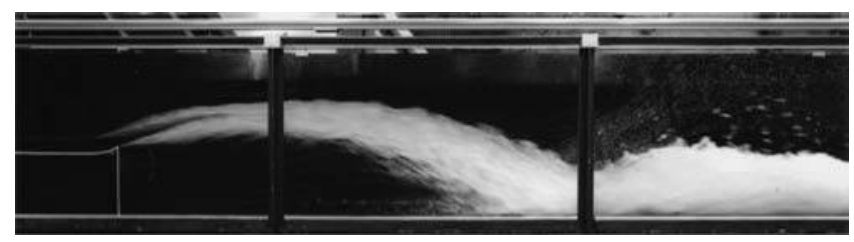



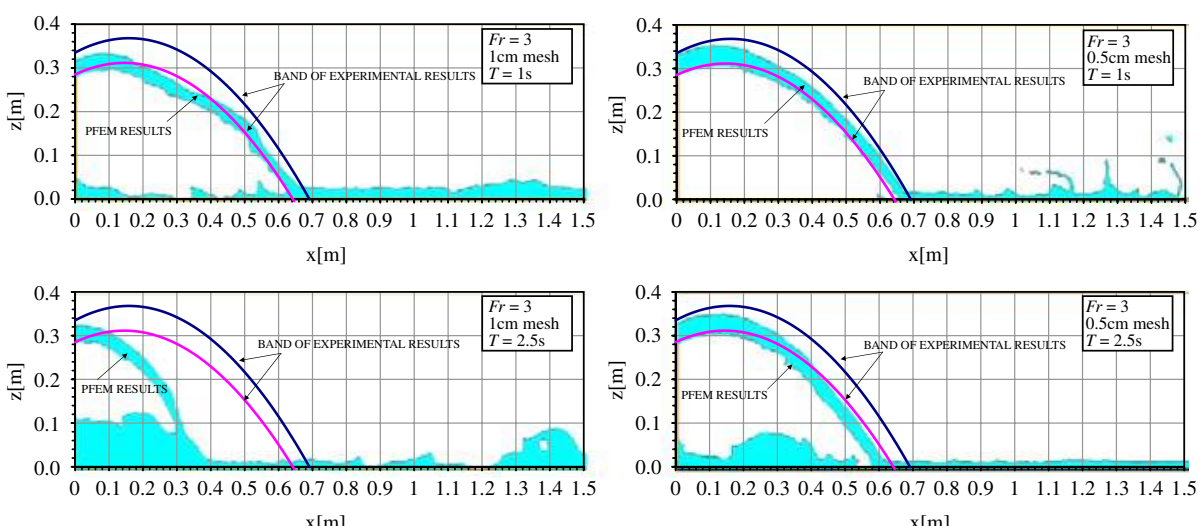

$\mathrm{x}[\mathrm{m}]$

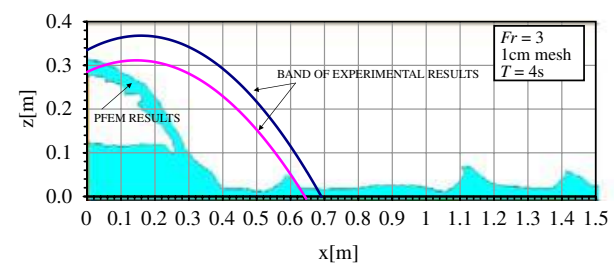

(a) $1 \mathrm{~cm}$ mesh

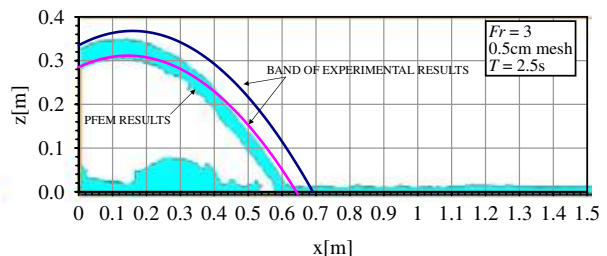

$\mathrm{x}[\mathrm{m}]$

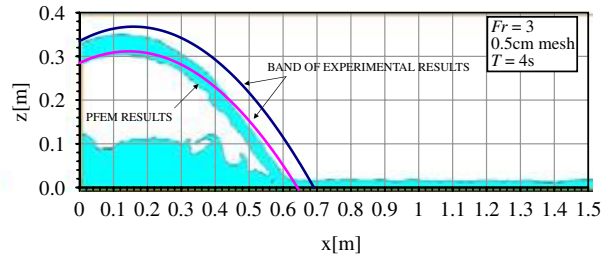

(b) $0.5 \mathrm{~cm}$ mesh

\section{Validation of the PFEM}

397
Figure 16.

Flip bucket. $F r=3$. Jet development for different mesh sizes

\begin{tabular}{lccc}
\hline & \multicolumn{3}{c}{$\begin{array}{c}\text { Range of } X \text { coordinate of the jet touching point } \\
1 \mathrm{~cm} \text { mesh }\end{array}$} \\
\hline $\mathrm{Fr}=3$ & Analytical solution $(\mathrm{m})$ & \multicolumn{2}{c}{$0.5 \mathrm{~cm}$ mesh } \\
$\mathrm{Fr}=5$ & $0.642-0.691$ & $0.315-0.345 \mathrm{~m}$ (50 percent) & $0.595-0.645 \mathrm{~m}$ (7 percent) \\
$\mathrm{Fr}=7$ & $0.642-0.691$ & $1.292-1.396 \mathrm{~m}$ (10 percent) & $1.276-1.395 \mathrm{~m}$ (0.5 percent) \\
& $0.642-0.691$ & $1.975-2.055 \mathrm{~m}$ (7 percent) & $2.185-2.295 \mathrm{~m}$ (6 percent)
\end{tabular}

Note: Figures in parentheses represent "average error"

Table II.

Flip bucket. Accuracy of the PFEM in reproducing the jet impact point

\subsection{Flip bucket 3D model}

The second part of Juon and Hager (2000) experiment considered the effect of a variable invert angle $\left(\beta\right.$ can vary from $0^{\circ}$ to $30^{\circ}$ ). This creates a restriction of the channel over the flip-bucket (Figure 20). A 3D model is built using surfaces that reproduce the geometry of the entire experimental setting (21).

The plane and side development of this wave is the output analyzed in this section. The main problem with this model is the presence of an incoming fluid. The initial mesh has some 72,000 three-noded triangular elements. This number increases after very few seconds of processing, arriving at 1.5 million tetrahedra elements. Calculation time is too long to permit the implementation of all the cases of the 2D analysis. Hence, only one model for each Froude number was built with a constant mesh dimension of $\Delta x=0.01 \mathrm{~m}$. 
EC

25,4

\section{8}

Figure 17.

Flip bucket.

Non-dimensional pressure head: $F r=3$ after $4 \mathrm{~s}$
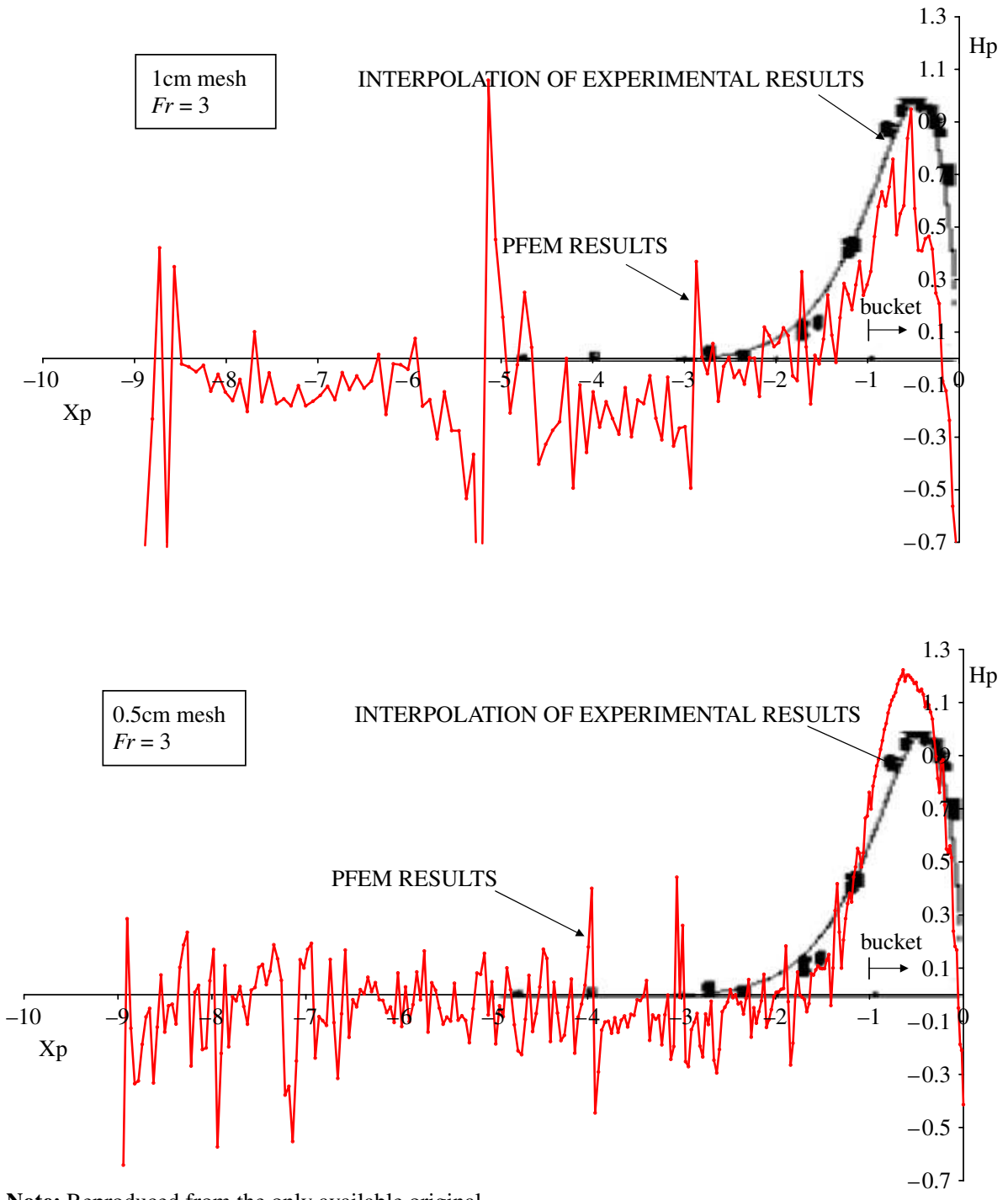

Note: Reproduced from the only available original

Two sides of the shock wave were analyzed: the $X-Y$ and the $X$ - $Z$ trajectory, as mentioned in Section 2. It was difficult to extrapolate clear images from the PFEM results as the development of such a wave it is not isolated from the flow but it is part of it.

Figures 20-24 show that, the side development of the shock wave is well reproduced and it also agrees well with the experimental data. It is more difficult to visualize the good simulation of the planar trajectory that only is qualitatively compared (Figure 25). In any case, the expected behavior is confirmed. 


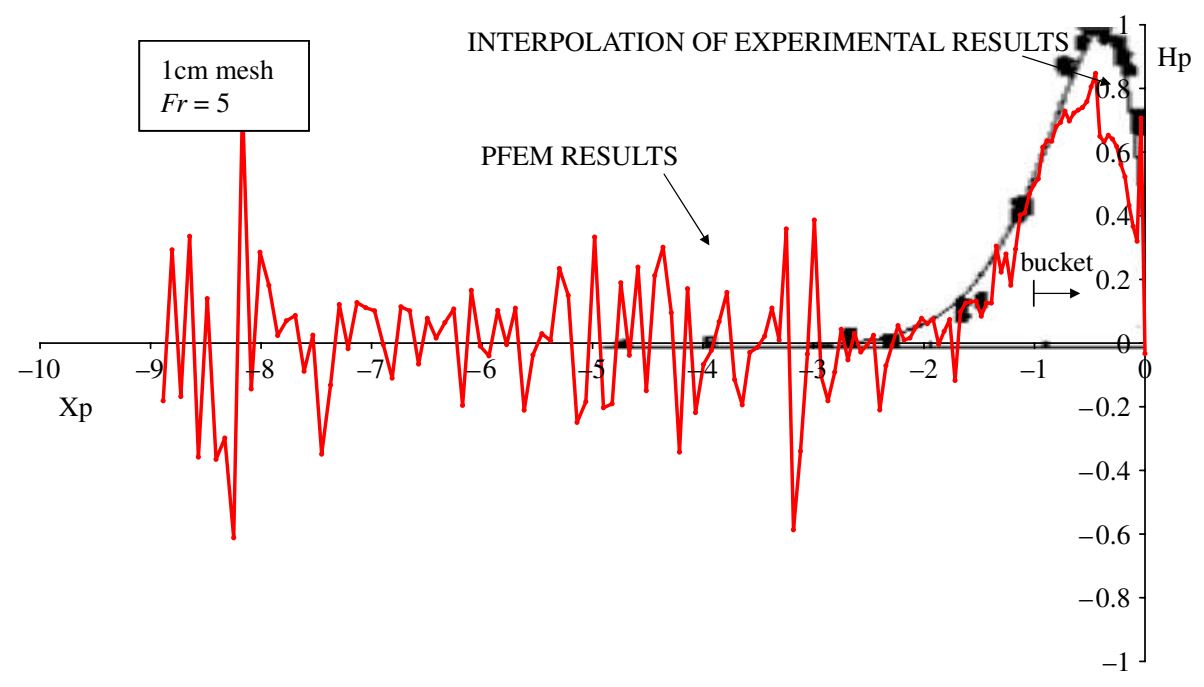
of the PFEM

399

$0.5 \mathrm{~cm}$ mesh $\mathrm{Fr}=5$

Note: Reproduced from the only available original
Figure 18.

Flip bucket. Non-dimensional pressure head: $F r=5$ after $4 \mathrm{~s}$

\section{Sluice gate}

One of the typical and mostly used discharge regulators is a sliding gate which controls the outflow of water. Examples of this kind of structure include the gates that are at the two ends of a chamber and the gates used to garrison the discharge channel of a dam. In this case, a simple planar sluice gate is the object of the analysis.

The specific discharge of the under seal flow is governed by the classical equation:

$$
q=a \cdot C_{\mathrm{c}} \sqrt{2 g h} ;
$$


EC

25,4

400

(1)

Figure 19.

Flip bucket.

Non-dimensional pressure head: $F r=7$ after $4 \mathrm{~s}$

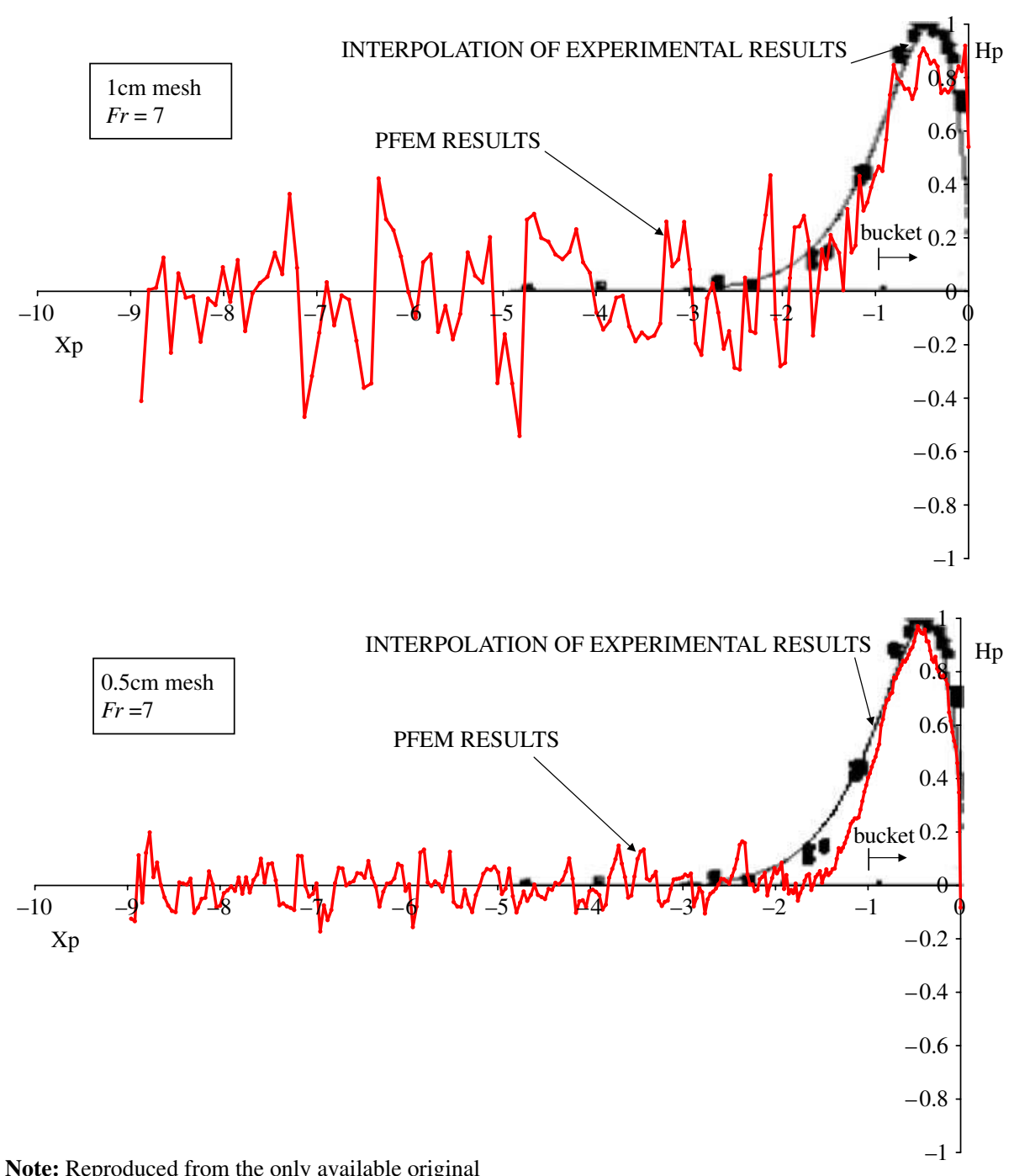

Note: Reproduced from the only available original

where $a$ is the height of the sliding gate from the bottom of the channel, $C_{\mathrm{c}}=0.611$ is the contraction coefficient and $h$ is the depth of upstream water.

The behavior of the under seal discharge and of the free surface contraction is analytically described and experimentally proved once the upstream condition and the geometrical data are given.

Next a step is placed at the end of the downstream channel in order to creating a slow discharge that, clashing with the fast under seal flow, generates an hydraulic jump. 

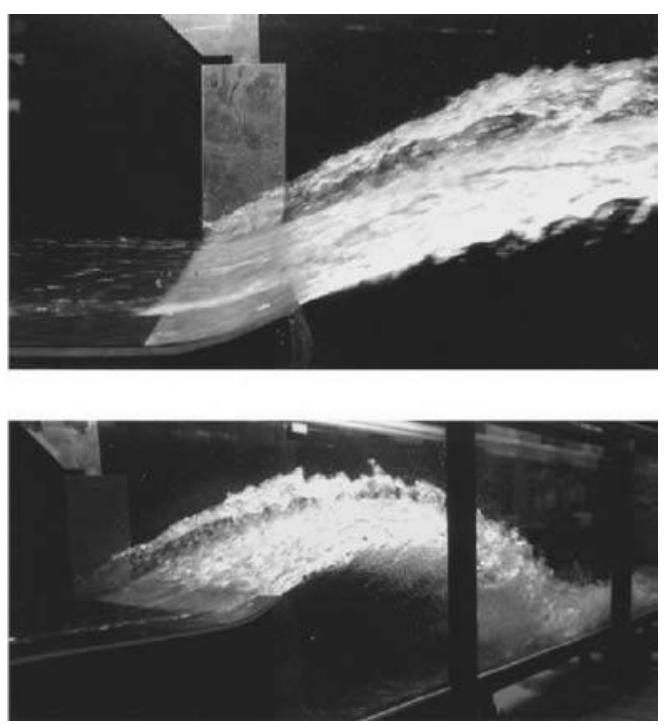

401

(a) Lateral views
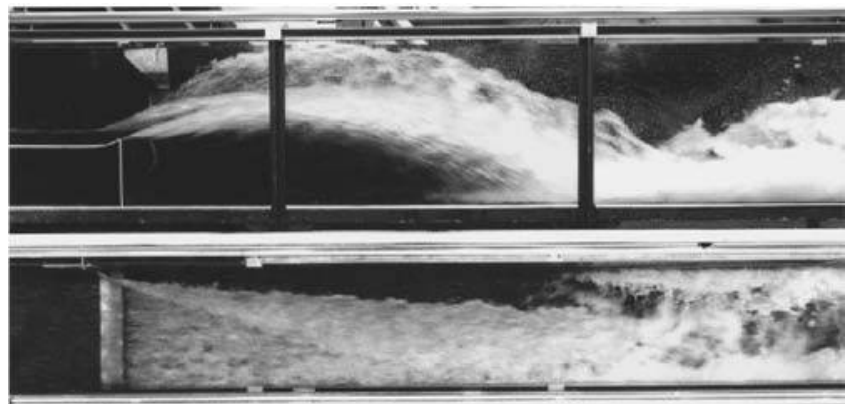

Figure 20.

Flip bucket. 3D

(b) Lateral and upper views

experiment

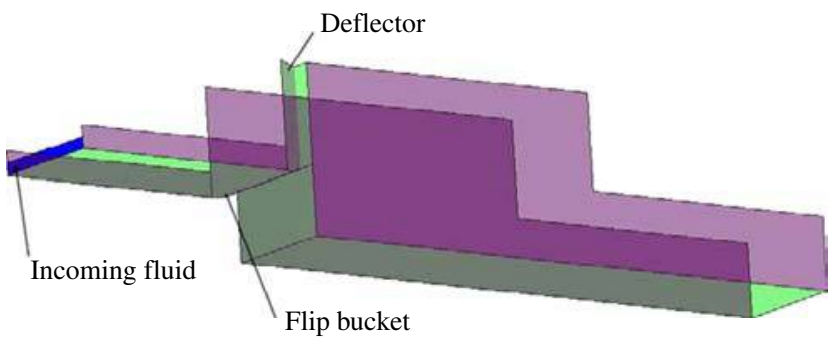

Figure 21 .

3D flip bucket. Geometry 
EC

25,4

\section{2}

Figure 22.

3D flip bucket. PFEM results
Figure 23.

3D flip bucket. Side view of PFEM results. The curve shows the average of experimental values
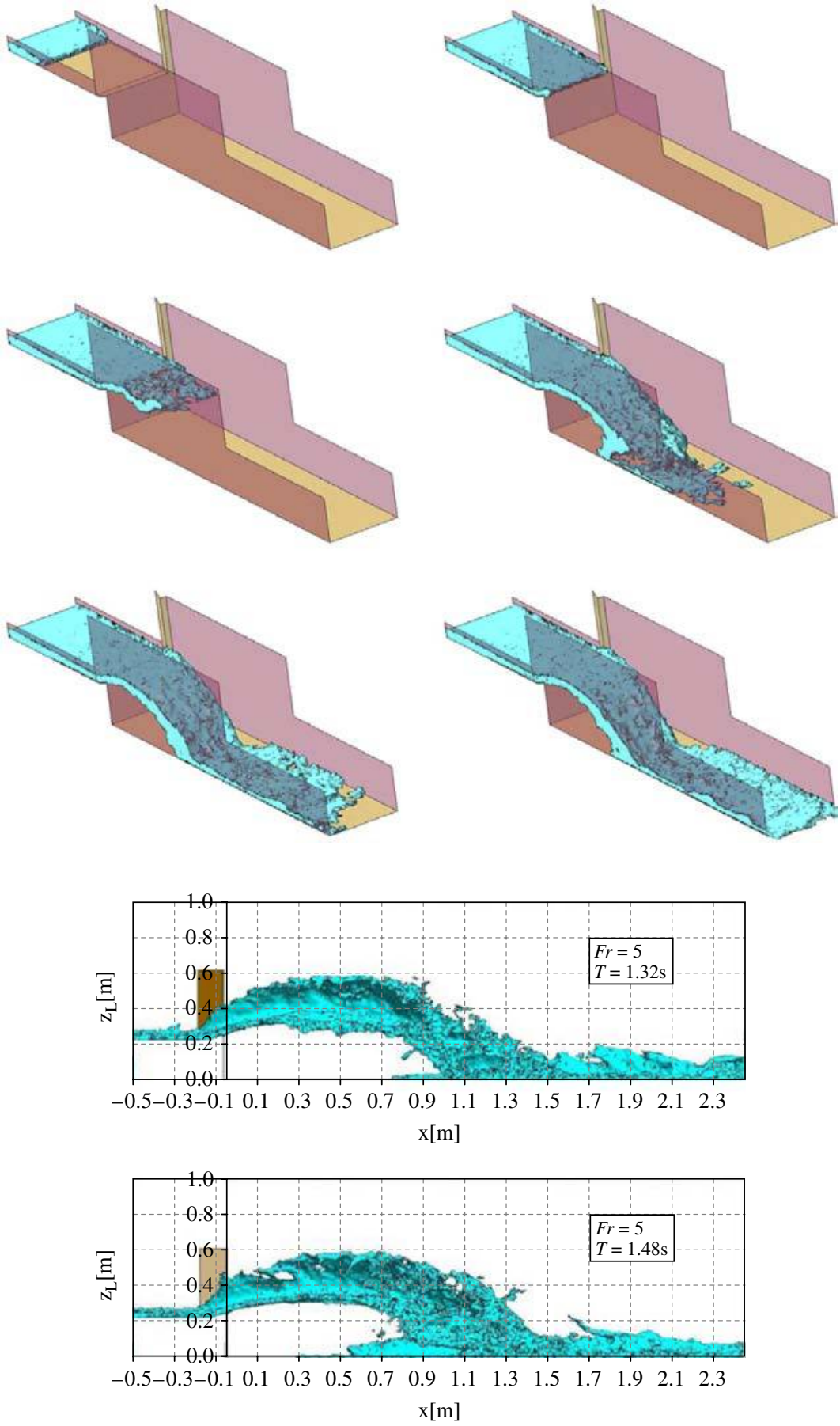

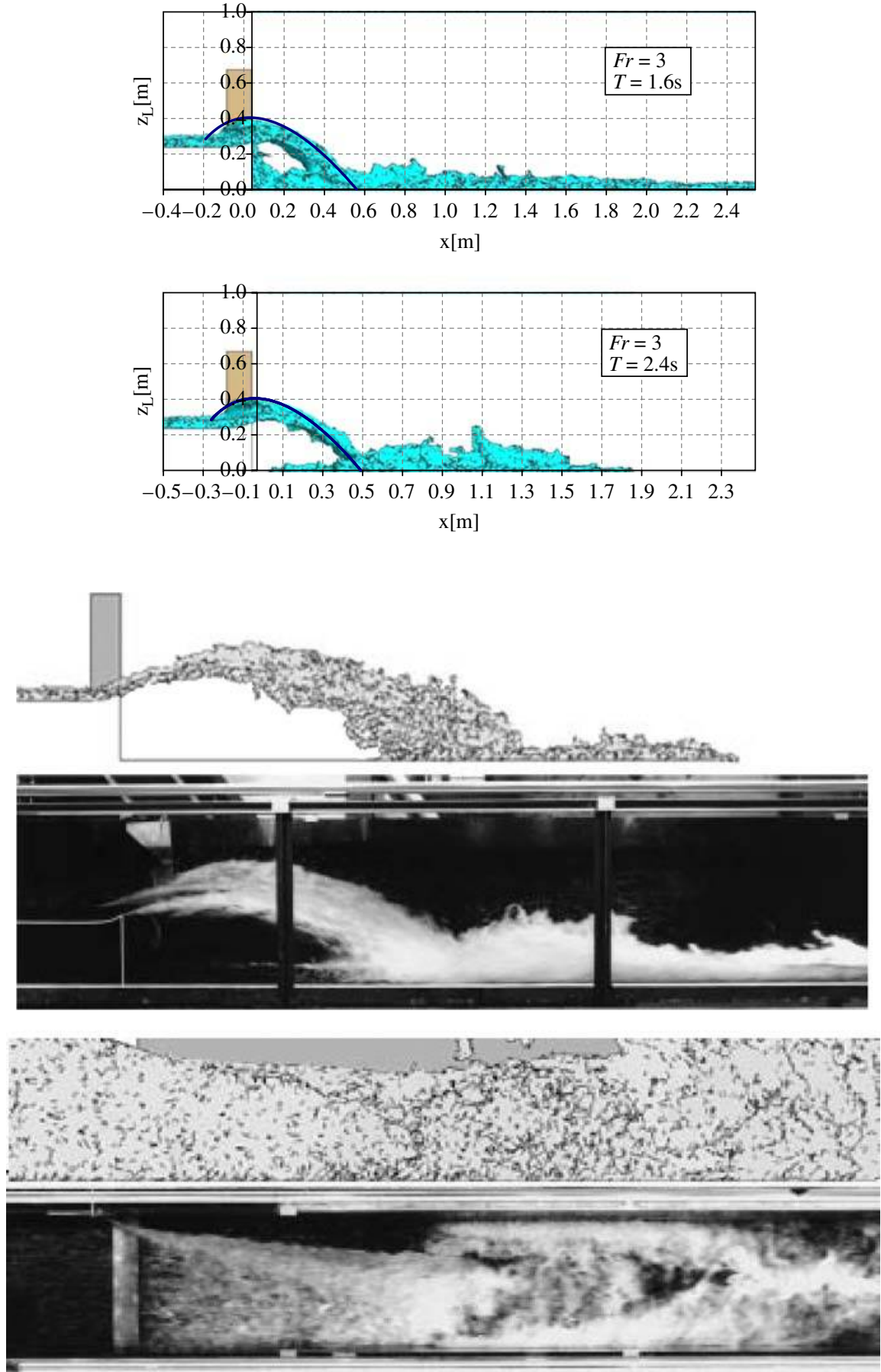

Validation of the PFEM

403

Figure 24 .

3D flip bucket. Side view of PFEM results. The curve shows the average of experimental values

Figure 25.

3D flip bucket. Comparison between the

PFEM results with the experimental photographs. Model with a $20^{\circ}$ deflector 
EC

25,4

404

\subsection{Experimental setting}

The experimental data used for the comparison are taken from the laboratory test carried out at the Hydraulic section of the Faculty of Civil Engineering of the University of Padua, Italy (Cola, 2002).

The experimental equipment is schematically shown in Figure 26 and it is composed of a plexiglas rectangular channel, its length is $1 \mathrm{~m}$ and its width is $0.3 \mathrm{~m}$. This channel leans on a beam that can be regulated for simulating different slopes. The inlet of the flow is controlled from the level of an upstream surge tank ( $V_{\mathrm{c}}$ in Figure 26). Downstream the channel there is a second reservoir where water falls in. An electrical pump permits the passage of water from the downstream tank to the upstream one; therefore a closed circuit with constant discharge is created. At the end of the channel there is a flap blade that can be regulated for generating the downstream conditions wanted. About 16 pressure intakes are connected with some piezometers, seven of them are inserted in the sluice gate while the rest is placed in the channel bottom.

\subsection{D PFEM model}

A 2D approach is sufficient to reproduce the phenomenon of the under seal flow. The kind of gate chosen can influence the contraction condition of the flow. In this case a $1 \mathrm{~cm}$ thin planar gate is set (Figure 27). Kirchhoff showed that if the gate is lifted up a distance which is much smaller than the gate width, the contraction coefficient $C_{\mathrm{c}}$ can be calculated as (Ghetti, 1984):

$$
C_{\mathrm{c}}=\frac{\pi}{2+\pi}=0.611
$$

Figure 26.

Schematic representation of the experimental device

Figure 27.

Sluice gate model. A detail

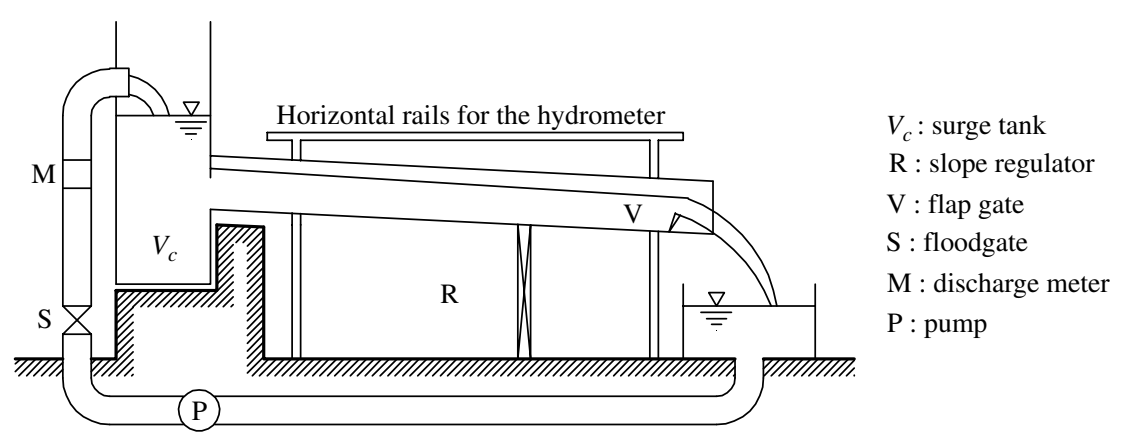

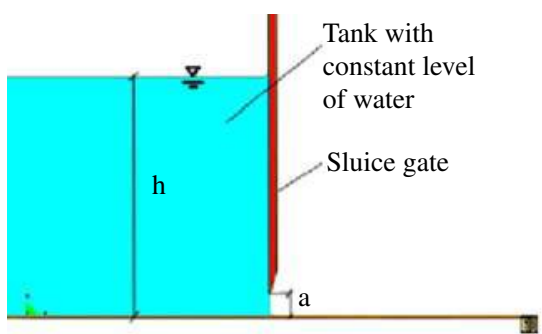

(a)

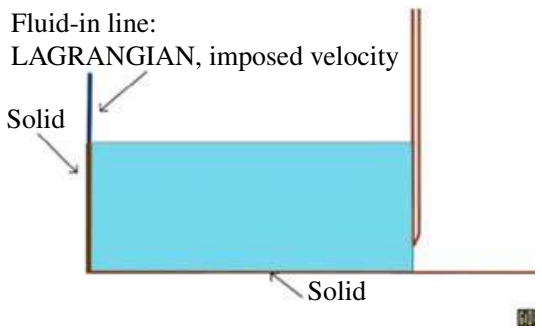

(b) 
Different numerical models were built for reproducing a system that represents the real setting of an upstream tank with a constant level of water. The volume of liquid in the upstream reservoir is already present at the beginning of the simulation. A balance of the inflow and the outflow in the reservoir is ensured by a continuous generation of fluid: the same discharge coming out under gravity force is brought in. The inflow is again modeled in a Lagrangian way, which originates a perturbation of the level of the reservoir. In fact, the inlet has to be inserted over the maximum level of water in the tank, otherwise the presence of fluid would made impossible the pushing forward of the entering flow (Figure 27).

The value of the discharge was one of the input data: for the first two models shown in Figure 28 it is $q=103.31 / \mathrm{sm}(Q=311 / \mathrm{s})$. Once the height $(y)$ of the inlet is set and knowing the value of the specific discharge $(q)$ coming out from the sluice gate, the initial velocity is given by:

$$
v=\frac{q}{y}
$$

Models 1 and 2 (Figures 29 and 30) have been used to verify the good behavior of the under seal flow using the PFEM. Three parameters have been analyzed:
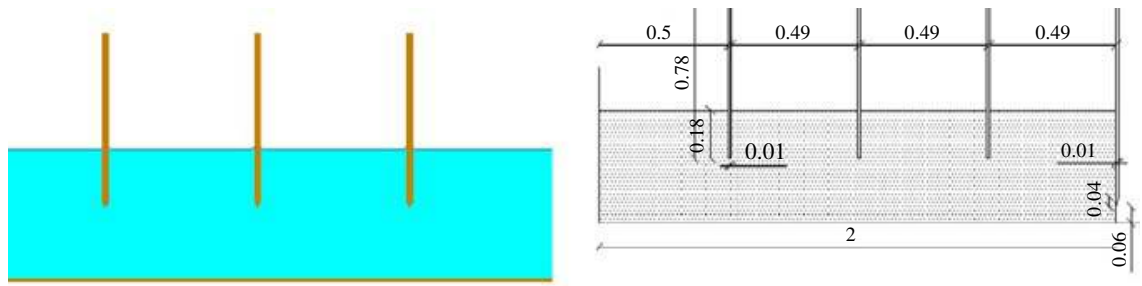

(a) Model 1: Three interior fixed gates
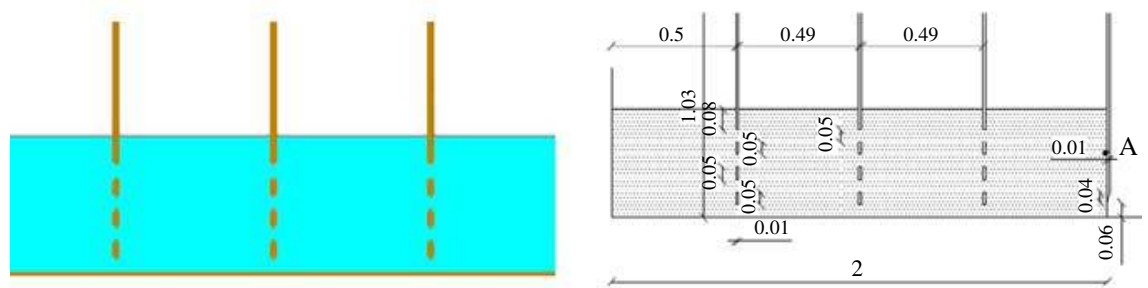

(b) Model 2: Three interior holed fixed gates
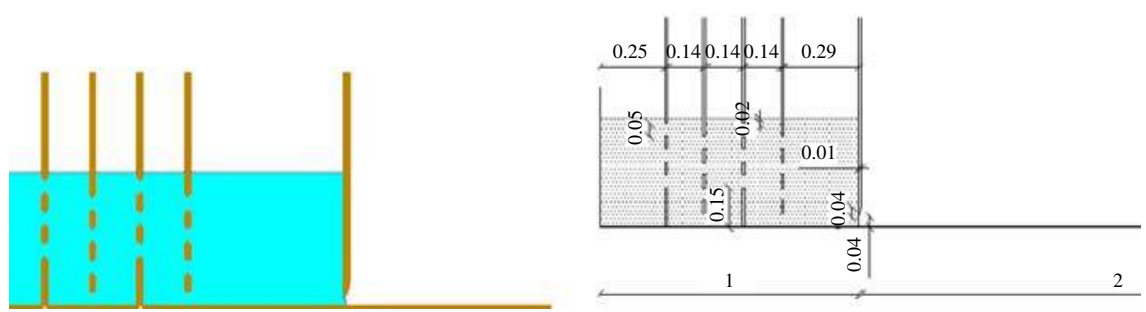

(c) Model 3: Three interior gates with staggered holes

\section{Validation of the PFEM}

405 
EC

25,4

406
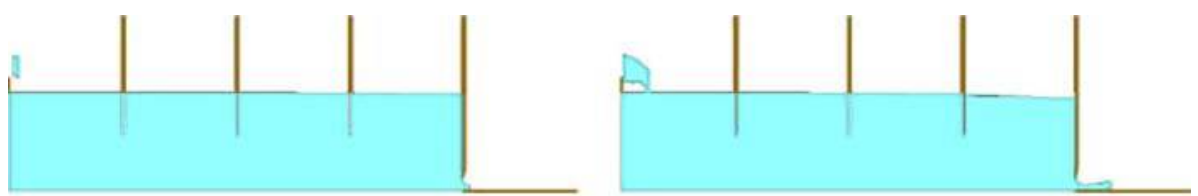

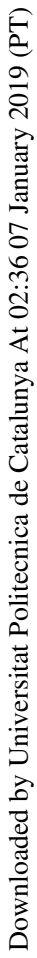

Figure 29.

Sluice gate. Model 1.

Simulation of the flow at different instances
Figure 30.

Sluice gate. Model 2.

Simulation of the flow at different instances
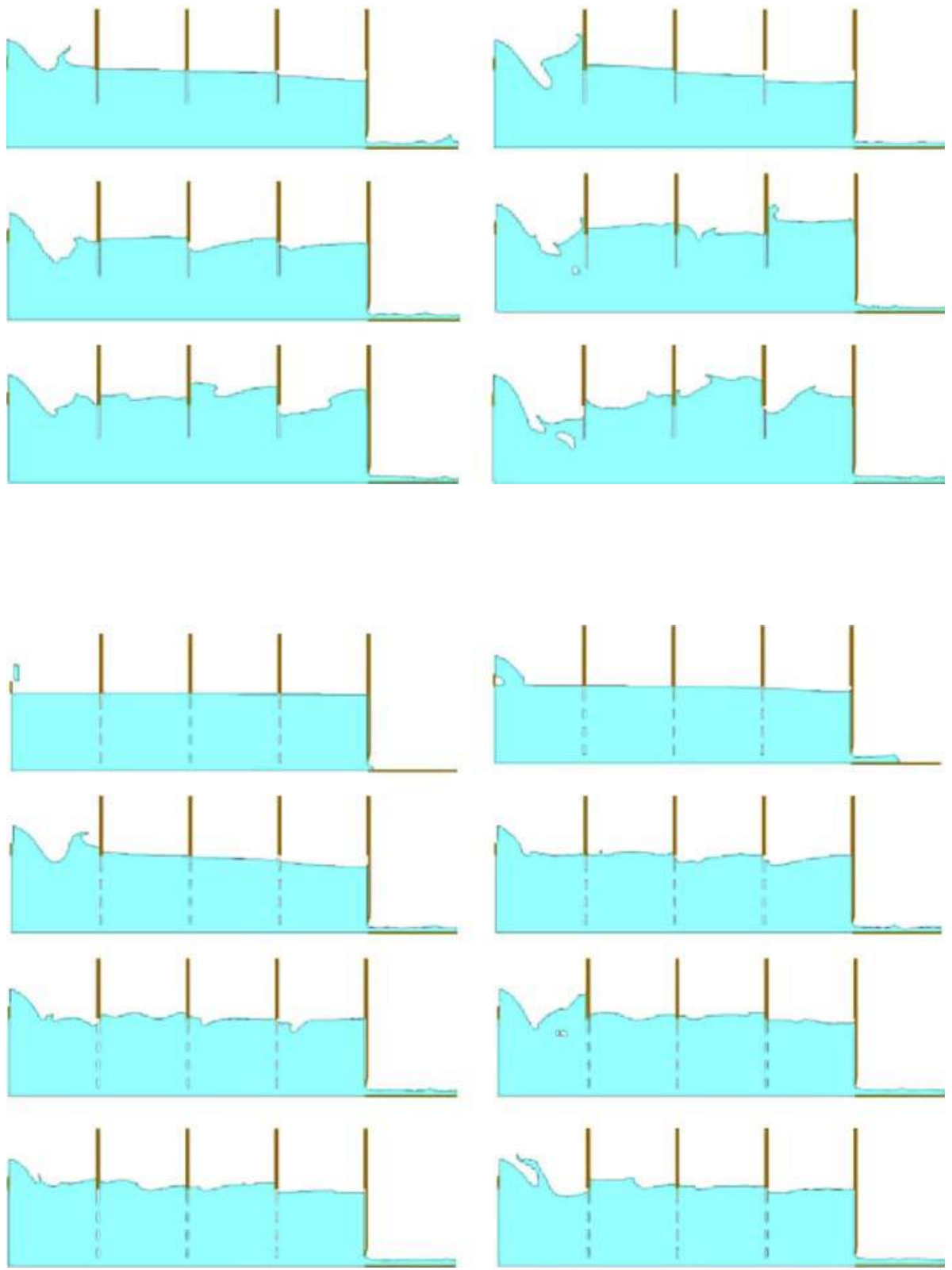
(1) the pressure along the gate;

(2) the outing discharge; and

(3) the free surface of the downstream water.

The initial dimension of the mesh is $\Delta_{x}=1 \mathrm{~cm}$. The depth of the water in the tank, following equation (11), is $h=0.433 \mathrm{~m}$.

A third model (Model 3 in Figure 28) has been used to verify the possibility of 407 reproducing a localized phenomenon such as the hydraulic jump generated by the clash of an upstream fast discharge with a downstream slow discharge. In Model 3, as during the experiment, the boundary conditions are created by the simultaneous action of the sluice gate leads to a fast discharge $\left(F r^{\circ} \geq 1\right)$ and of a step at the right side of the model, that generates a transition from fast to slow flow to gain energy (Ghetti, 1984). In this case, the discharge of the model is $Q=21.1 \mathrm{l} / \mathrm{s}$ and the sluice gate is raised a distance of $a=4 \mathrm{~cm}$. The initial dimension of the mesh is $\Delta_{x}=0.8 \mathrm{~cm}$. The depth of water in the tank, following equation (11) is $h=0.422 \mathrm{~m}$.

\subsection{The pressure along the gate}

The measurements performed at the University of Padua were conducted using 7 piezometers on the sluice gate as shown in Figure 31. The value of the capillary migration was taken as $4.43 \mathrm{~mm}$. This was calculated using Jurin equation (Ghetti, 1984).

Assuming an irrotational fluid, the energy which is present into the stream tube can be considered constant. This means that because of the growing of velocity in the zone near the opening of the sluice gate, the pressure head has to drop drastically, compared with the hydrostatic value.

Figures 32 and 33 show the comparison between the experimental results for the pressure head and the computational output, for different instances for Models 1 and 2 shown in Figure 28 in Section 4.2 (Table III).

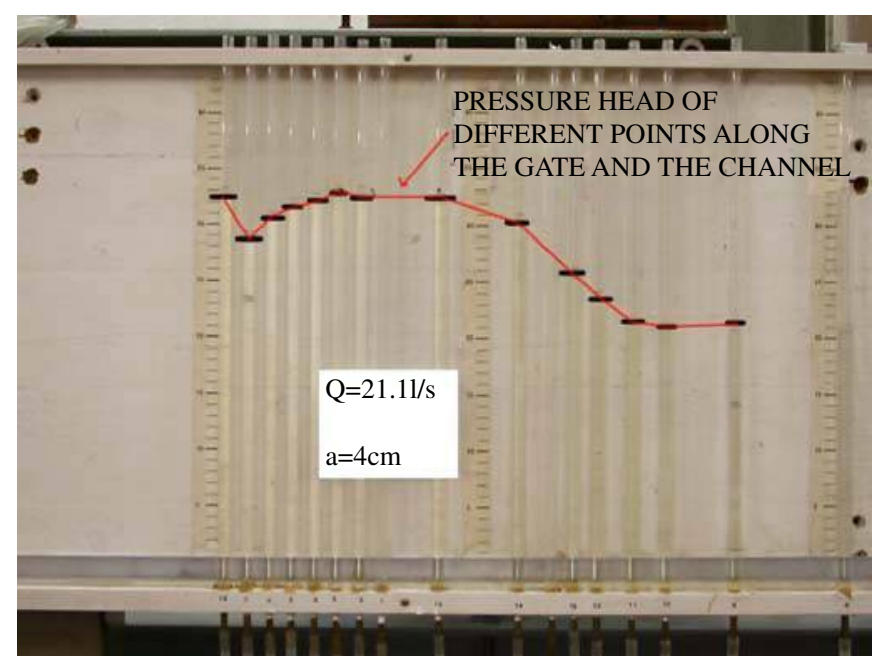

Figure 31 .

Sluice gate. Piezometers 
EC

25,4

408

Figure 32.

Sluice gate. Model 1.

Pressure head

distribution. A-hydrostatic distribution:

B-experimental values, C-PFEM results
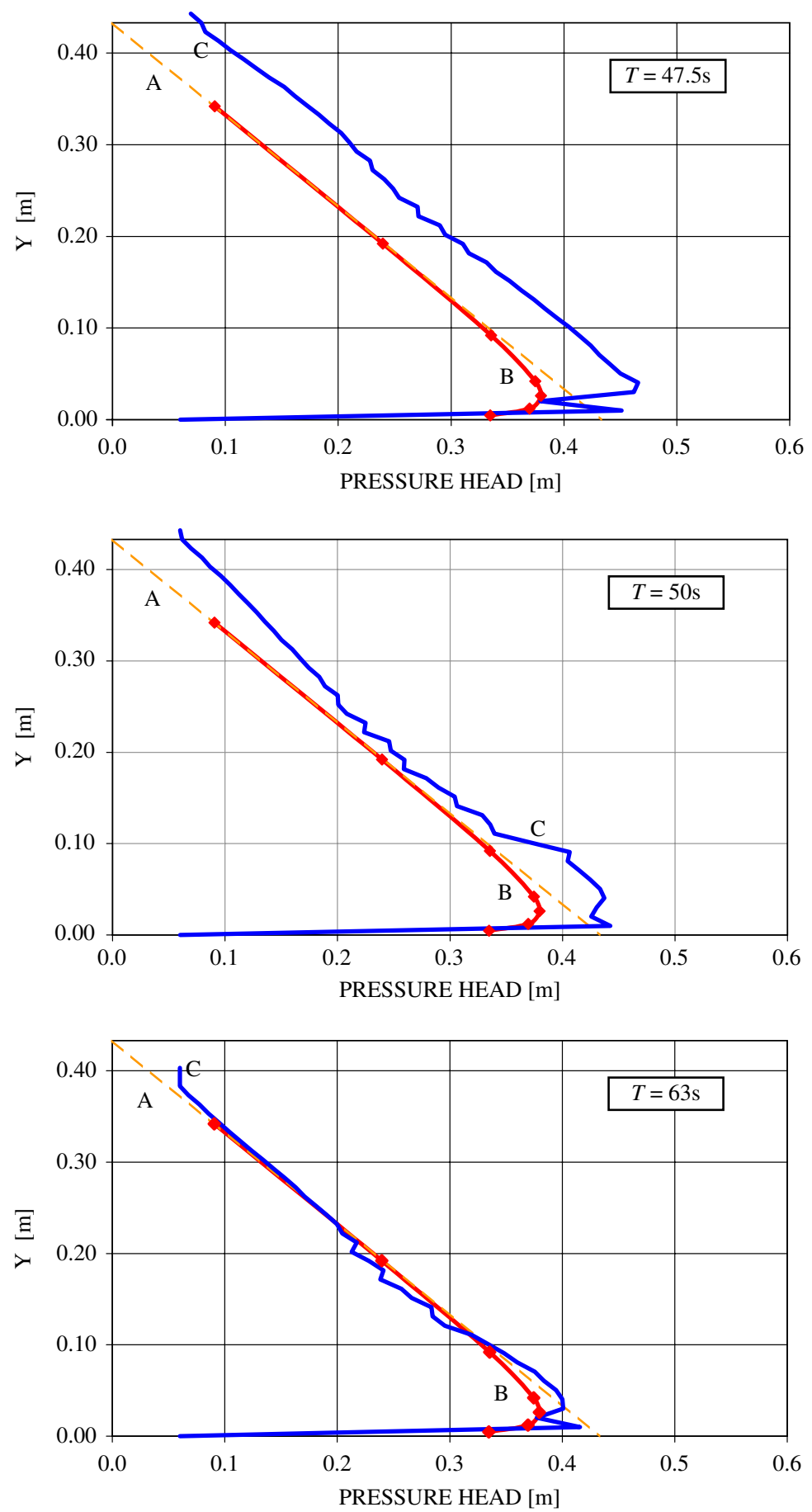

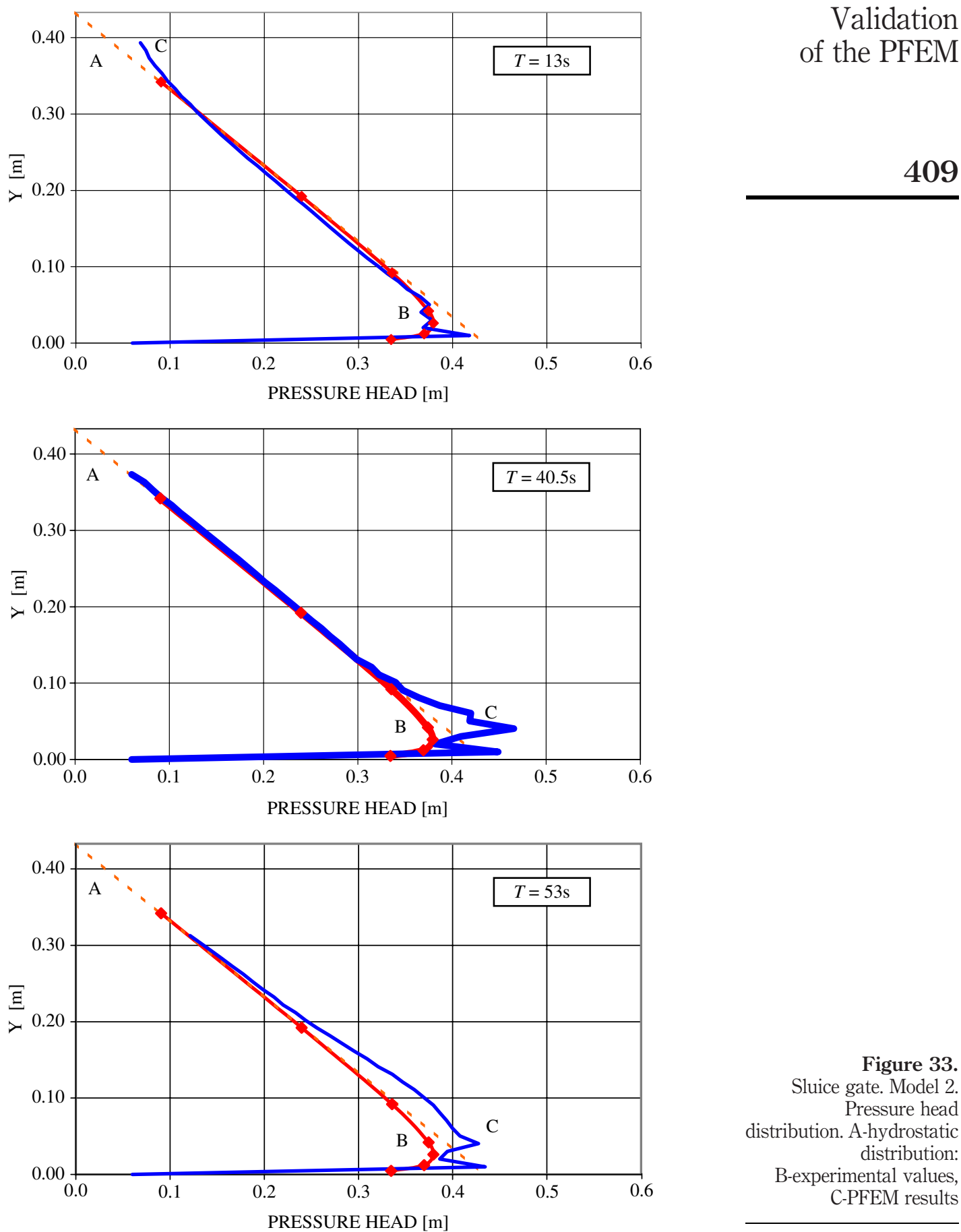

Figure 33. Sluice gate. Model 2.

Pressure head distribution. A-hydrostatic distribution: B-experimental values, C-PFEM results 
EC

25,4

410

As expected, the model with holed gates (Model 2) gives an upstream depth that is more regular and less subjected to waves due to the constant entrance of fluid. This yields a very good comparison with the experimental results as shown in Figure 33. On the contrary, looking at the results for Model 1 with standard gates, the dynamic effect increases the value of the pressure head as shown in Figure 32(a) and (b).

Figure 34 clearly shows the oscillation of pressure at a point in the middle of the sluice gate. The oscillations are acceptable if compared with the average of experimental values (the horizontal line). The standard deviation is about 11 percent.

\subsection{The outing discharge}

The discharge of the under seal flow is completely defined if the geometrical characteristics are fixed and the depth of water in the tank is given. Analyzing a single section of the outing flow we would risk to be influenced by local effects. This is the reason why, we have integrated the velocity diagram of more than one vertical section of water for the same time instant. We consider many ideal vertical sections located at different distances from the sluice gate. The error in the discharge evaluation is always lower that 10 percent. Excluding isolated phenomena due to the variation of the water level in the tank, the PFEM results can be considered very accurate (Figure 35).

\subsection{The analysis of the free surface of the downstream water}

As mentioned in Section 4.2 a thin and planar sluice gate causes a contraction of the free surface of the flow, which depends on a contraction coefficient $C_{\mathrm{c}}=0.611$ (Figure 35, Ghetti, 1984). That is, the depth of water of the under seal flow has to arrive at $a C_{\mathrm{c}}$, where $a$ is the level of gate lift.

Looking at the oscillations of the free surface, they are more or less of the same order than the dimension of the mesh 34 .

Looking at the values of water depth in the interval between 10 and $50 \mathrm{~cm}$ from the sluice gate and calculating an average depth, we obtain quite good results in comparison to the standard deviation, as shown in Table IV.

\subsection{The hydraulic jump}

The hydraulic jump is an interesting phenomenon of energy dissipation generated by the clash of an upstream fast discharge with a downstream slow discharge. Many forms of hydraulic jump exist and basically they are characterized by the Froude number of the upstream discharge. We consider that for a generic section the total thrust is composed of two different parts (Figure 36):

Table III.

Experimental pressure head for $Q=31 \mathrm{l} / \mathrm{s}$

\begin{tabular}{lcccc}
\hline Piezometer & $H(\mathrm{~cm})$ & $h=h-4.43 \mathrm{~mm}(\mathrm{~cm})$ & $z(\mathrm{~cm})$ & $h-z=P / \gamma(\mathrm{cm})$ \\
\hline 1 & 43.7 & 43.3 & 34.20 & 9.06 \\
2 & 43.4 & 43.0 & 19.20 & 23.76 \\
3 & 42.7 & 42.3 & 9.20 & 33.06 \\
4 & 41.1 & 30.7 & 4.20 & 36.46 \\
5 & 39.4 & 35.0 & 2.60 & 36.36 \\
6 & 35.8 & 29.6 & 1.20 & 34.16 \\
7 & 30.0 & & 0.48 & 29.08 \\
\hline
\end{tabular}


(1) the hydrostatic thrust:

$$
M_{\mathrm{hydr}}=\gamma \cdot A \cdot y_{G} ;
$$

and

(2) the dynamic thrust:

$$
M_{\mathrm{dyn}}=\rho \cdot Q \cdot v .
$$

An hydraulic jump is generated when the total thrust of the upstream discharge is equal to that of the downstream discharge. Once a control volume is defined, the momentum equation, together with the continuity equation (Ghetti, 1984; Cola, 2002), lead to a relationship between the upstream and the downstream flow depth. For a rectangular channel:

$$
\frac{y_{2}}{y_{1}}=\frac{-1+\sqrt{1+8 \cdot F r_{1}^{2}}}{2} .
$$

Figures 37 and 38 compare the development of the free surface with the experimental data for the hydraulic jump.

The kind of hydraulic jump we analyze is a stationary one. The lighter line with dots plots the experimental values, whereas the darker line shows the PFEM results. Note that the computational results are given for much more points than those computed in the experiment. The agreement between experimental and PFEM results is noticeable.

Unfortunately, for a phenomenon like an hydraulic jump steady state and equilibrium between the upstream and downstream channel are not fully obtained after few seconds and only the qualitative behavior can be reproduced and measured.

\section{Dambreaking test}

Dambreaking tests are quite popular for validation of free surface flow codes. Experimental-numerical validation for such experiments is quite straightforward because of the simplicity of the set up: the collapse of a water column that overpasses a downstream obstacle. No special conditions are needed for the onset of the flow.

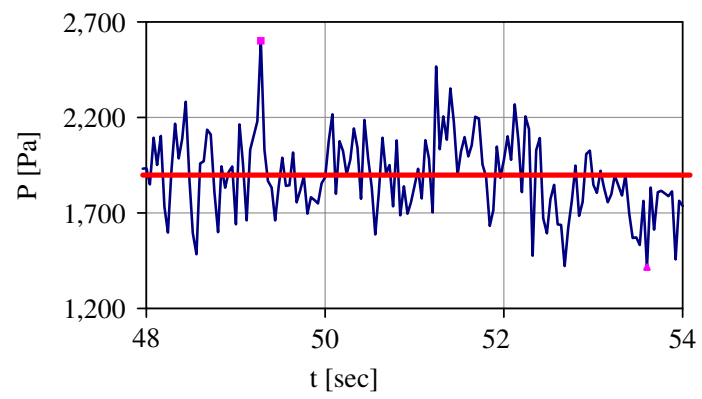

Figure 34. Sluice gate. Model 2. PFEM results for the time evolution of pressure at point A of Figure 28(b) of the sluice gate. The horizontal line shows the average of experimental results 
EC

25,4

\section{2}

Figure 35.

Sluice gate. Free surface after the gate showing the contraction of the flow
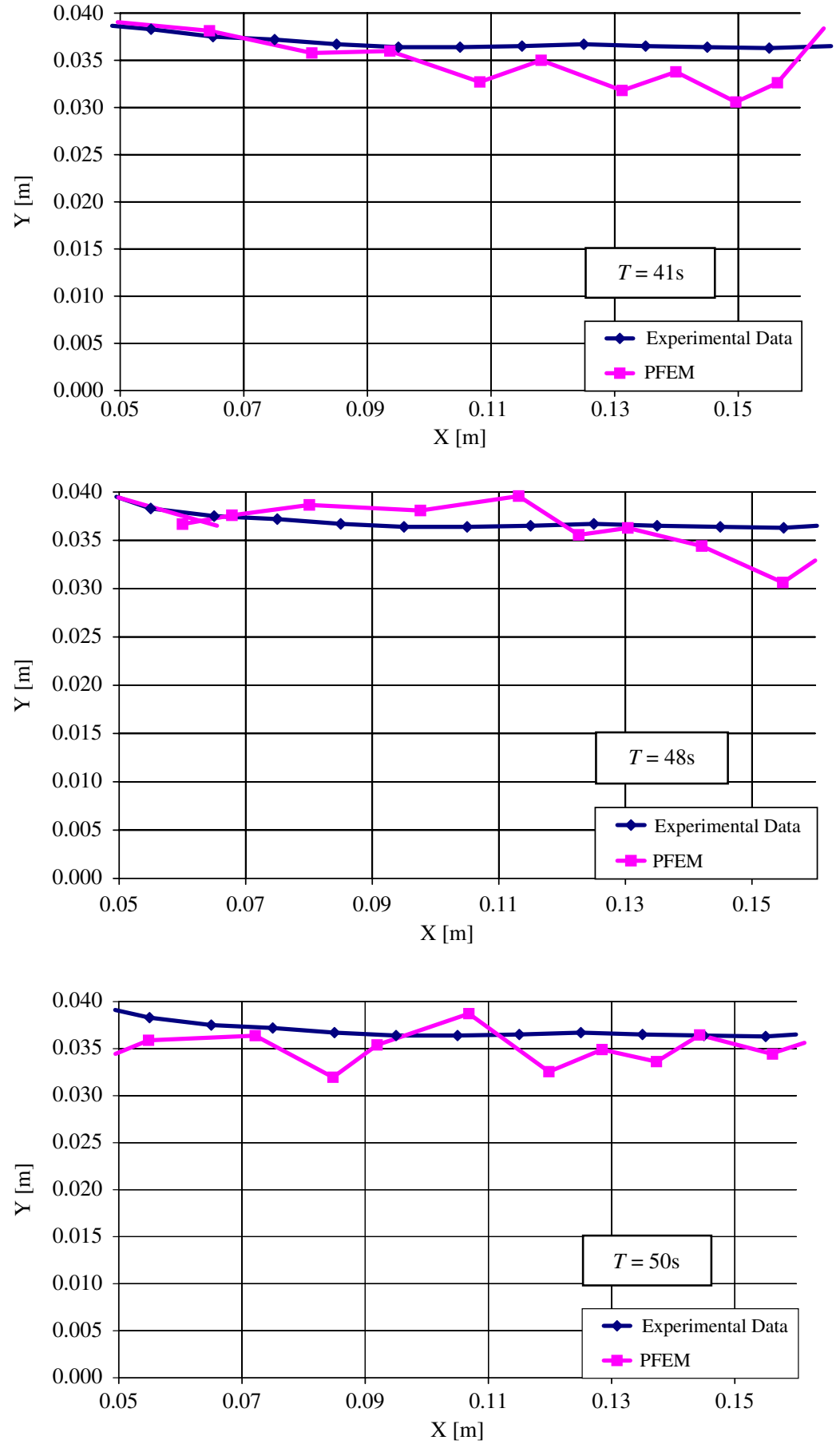
In our case, both a 2D and a 3D model are used for analyzing the jet trajectory and the pressure on the obstacle. Experimental data are taken from two different tests available in the literature. Both tests follow a very similar approach with a different geometry for the experimental set up.

\section{$5.12 D$ experiment}

The first experimental data are taken from a test used for validating of a particle method by Koshizuka et al. (1995).

The geometry used is shown in Figure 39, where $L=14.6$ and $h=2.4 \mathrm{~cm}$. In the real experiment, the box is made of glass and the water column is supported by a vertical wall which is drawn up in an approximated time of $0.05 \mathrm{~s}$. In the model, a vertical velocity of $5.84 \mathrm{~m} / \mathrm{s}$ is given to the opening gate assuming a uniform motion of the flow. The initial mesh size is $0.001 \mathrm{~m}$. The model has 50,000 nodes and nearly 100,000 three-noded triangles.

5.1.1 Trajectory comparison. Snap shots of the different instances of the experiment are shown for comparison with the PFEM results at the same times in Figures 40 and 41 .

The biggest difference can be noticed for the simulation times equal to 0.4 and $0.5 \mathrm{~s}$, i.e. when the jet touches the downstream wall. The air bubble which is trapped by the jet, is not captured well by the PFEM results. This is due to the fact that air particles are not modeled in our simulation.

\section{$5.23 D$ experiment}

A similar example was subsequently studied in 3D. The results were taken from the work presented at the Spheric Workshop held at the University La Sapienza of Rome in May 2006 (1st Spheric Workshop, 2006). The test is a 3D dambreak

\begin{tabular}{lccc}
\hline$t(s)$ & Medium depth $(\mathrm{m})$ & Theoretical value $(\mathrm{m})$ & SD \\
\hline 40 & 0.034 & 0.035 & 0.003 \\
45 & 0.032 & 0.035 & 0.004 \\
50 & 0.036 & 0.035 & 0.002
\end{tabular}

\section{Validation of the PFEM}

413 
EC

25,4

414

Figure 37.

Hydraulic jump. Free surface development
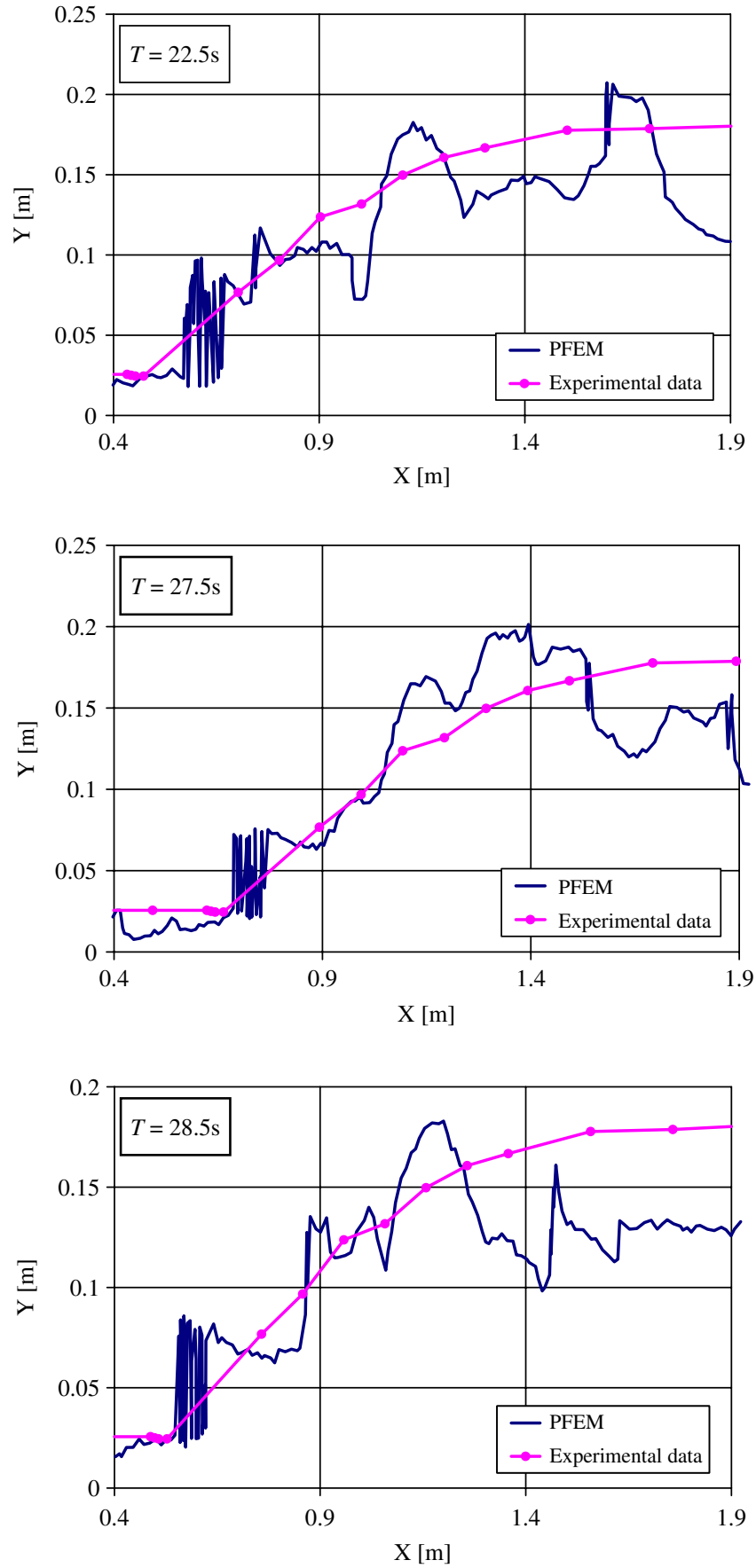

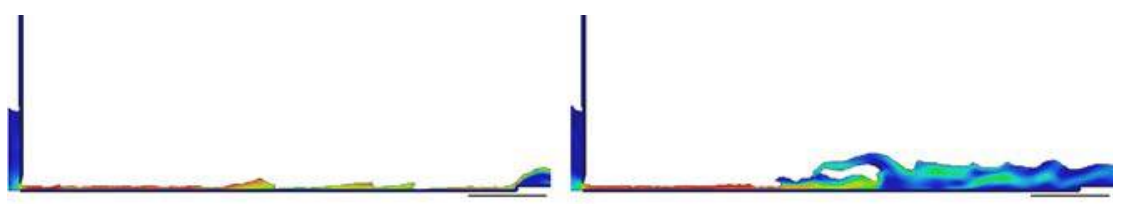

\section{Validation of the PFEM}
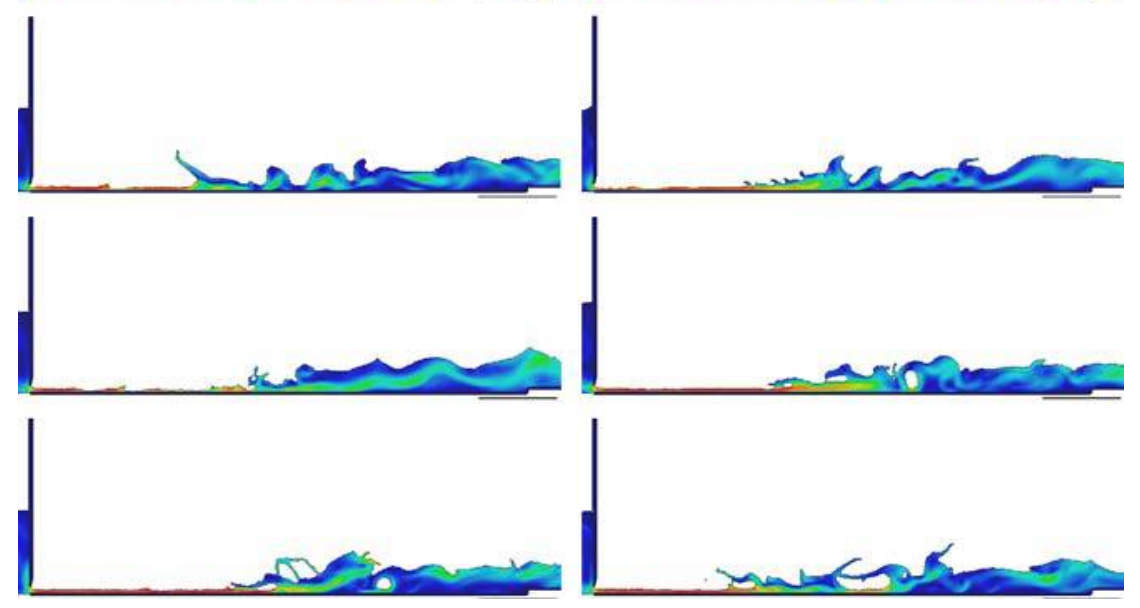

Figure 38.

Hydraulic jump. Colors indicate the average of the velocity modules

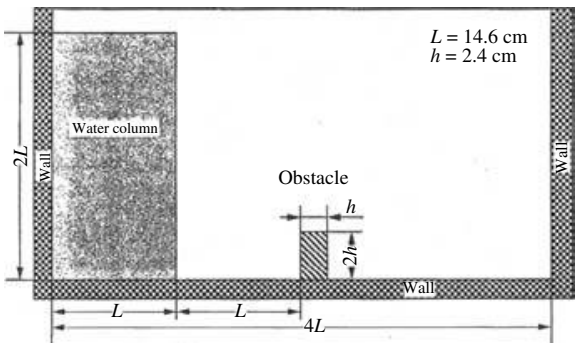

(a)

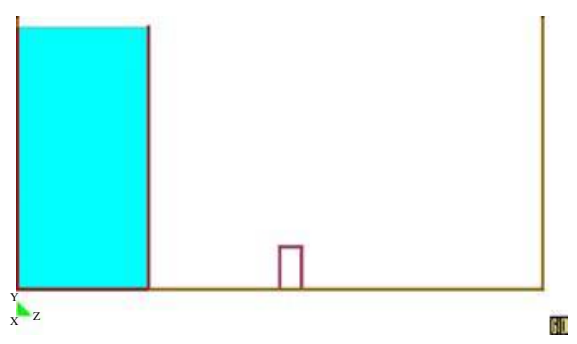

(b)
Figure 39.

2D dambreak. Set up: (a) experimental set up taken from Koshizuka et al. (1995); (b) PFEM model

represented in Figure 42. The 3D model reproduces the geometry of the experimental set up well described in Kleefsman et al. (2005) and follows the parameters of Figures 43-45.

5.2.1 Pressure comparison. The experimental value of the pressure measured at eight points in the step as shown in Figure 42 are compared with the PFEM results (Figures 46-49). The simulation is carried out over $6 \mathrm{~s}$ of real time. The behavior is well reproduced also if the two nearest points to the angle have some discordance with the pressure level at the wave impact point. The maximum pressure value is always higher in the numerical solution than in the real measurements.

Pressure values at points 1 and 6 are compared for two different PFEM models. As expected, a coarse mesh gives a lower precision. The finer mesh model has 50,000 points and 170,000 four-noded tetrahedra, whereas the coarse mesh has only 14,000 points and 60,000 tetrahedra elements (Figure 50). 
EC

25,4

\section{6}
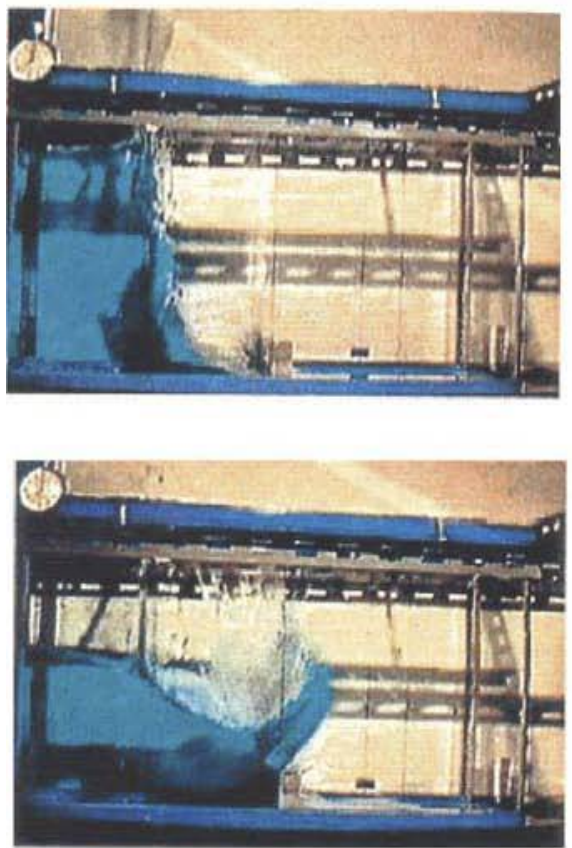

Figure 40.

2D dambreak.

Experimental results on the left (Koshizuka et al., 1995) compared with PFEM results at the same instance

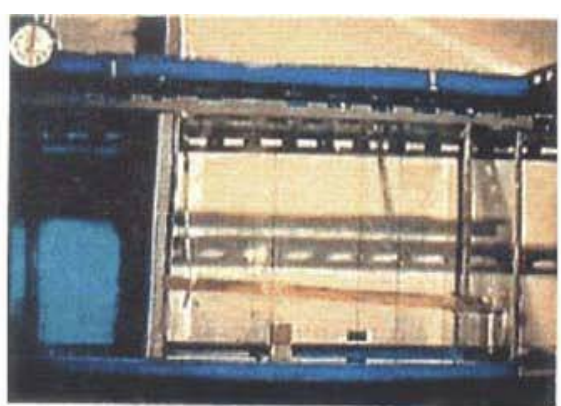

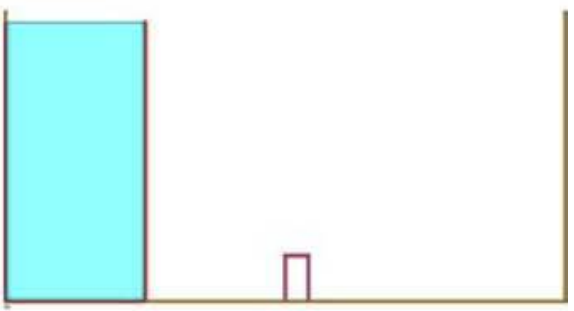
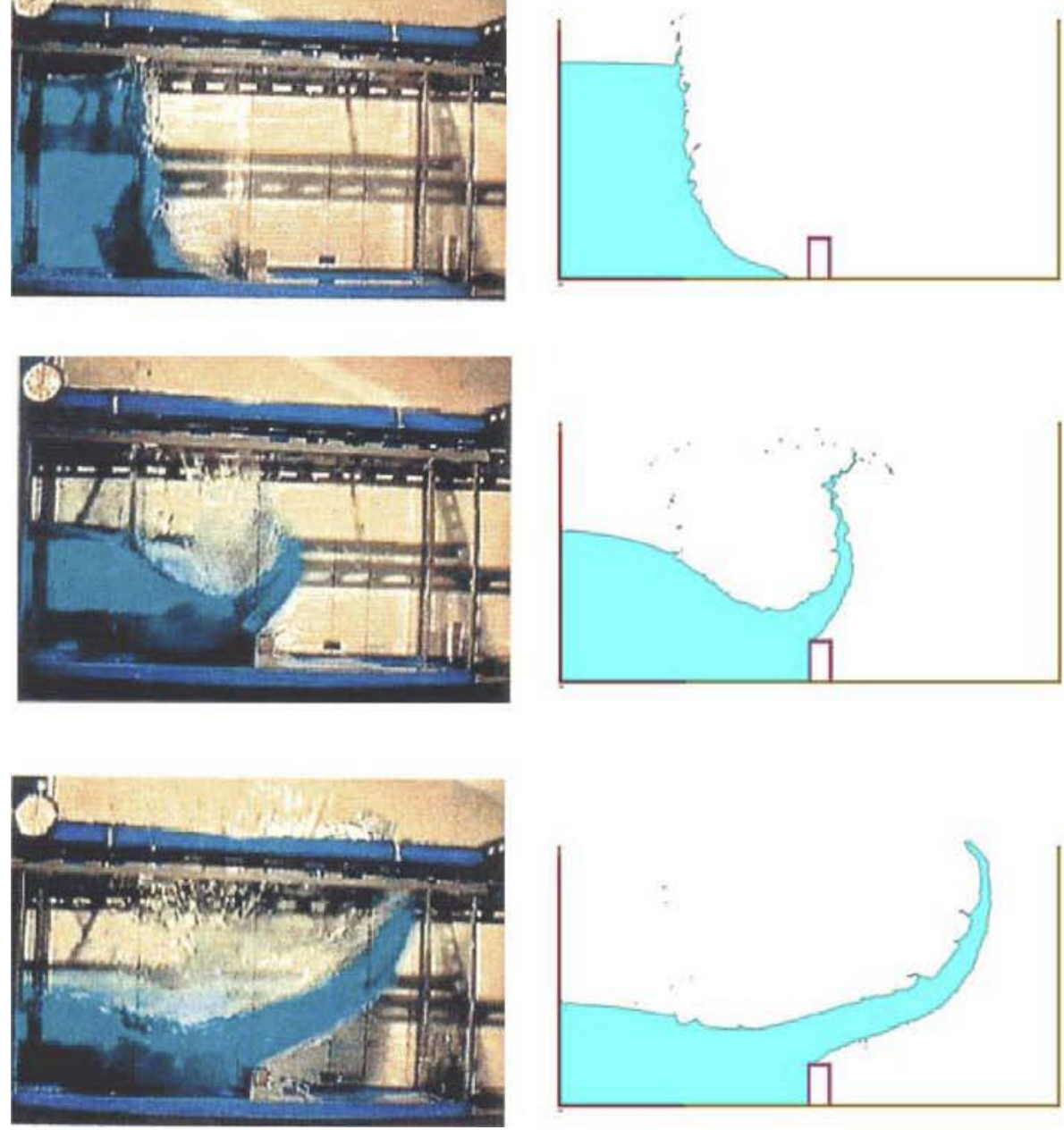

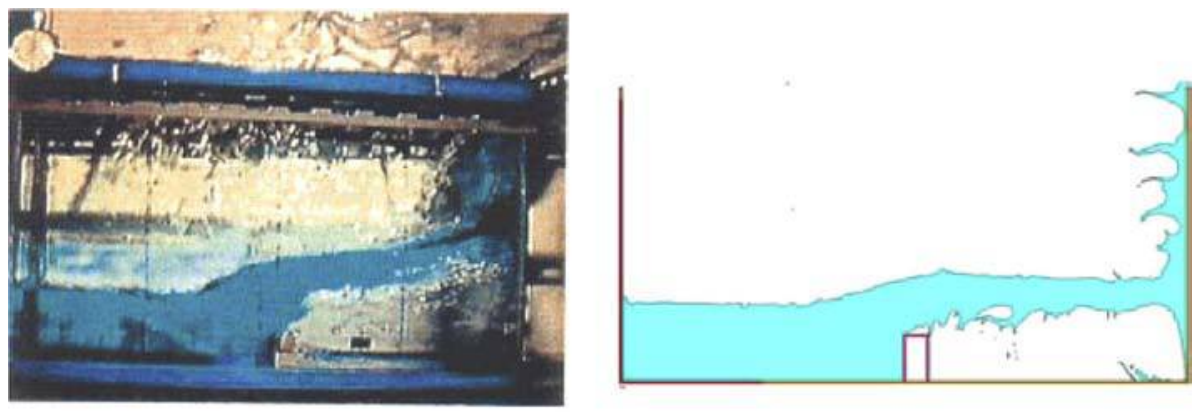

Validation of the PFEM
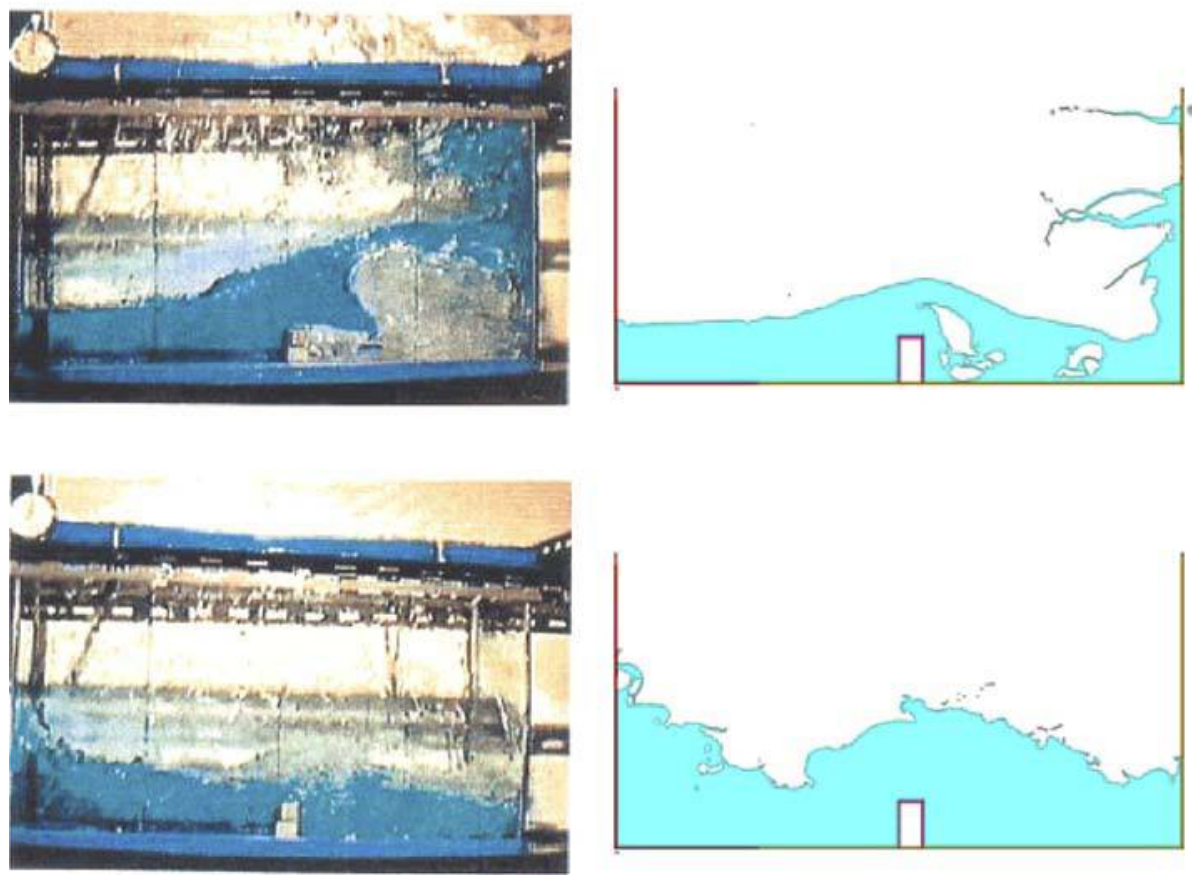

Figure 41. 2D dambreak.

Experimental results on the left (Koshizuka et al., 1995) compared with PFEM results at the same instance

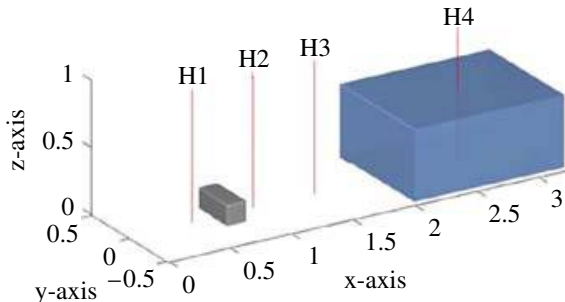

Source: 1st Spheric Workshop (2006)

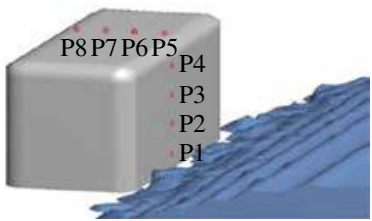

Figure 42.

Pressure measurement positions in the dambreak experiment 
EC

25,4

\section{8}

Figure 43.

3D dambreak. Geometry of the experimental set up

Figure 44.

3D dambreak. PFEM model

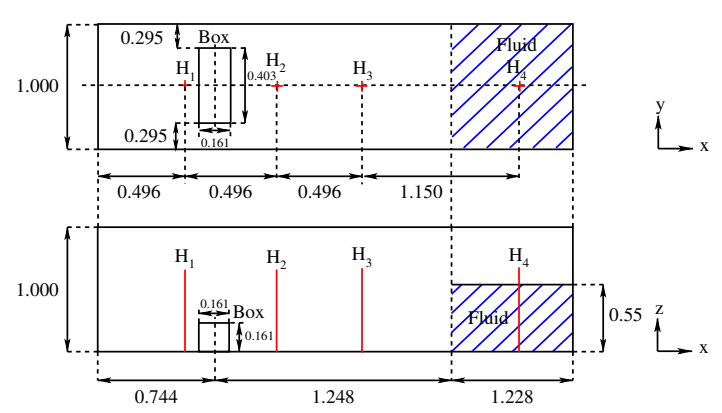

(a) Entire model

Source: 1st Spheric Workshop (2006)

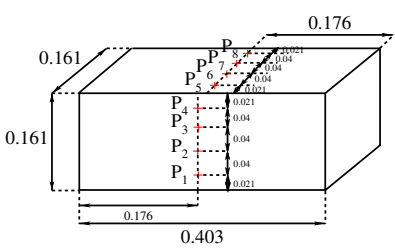

(b) Step
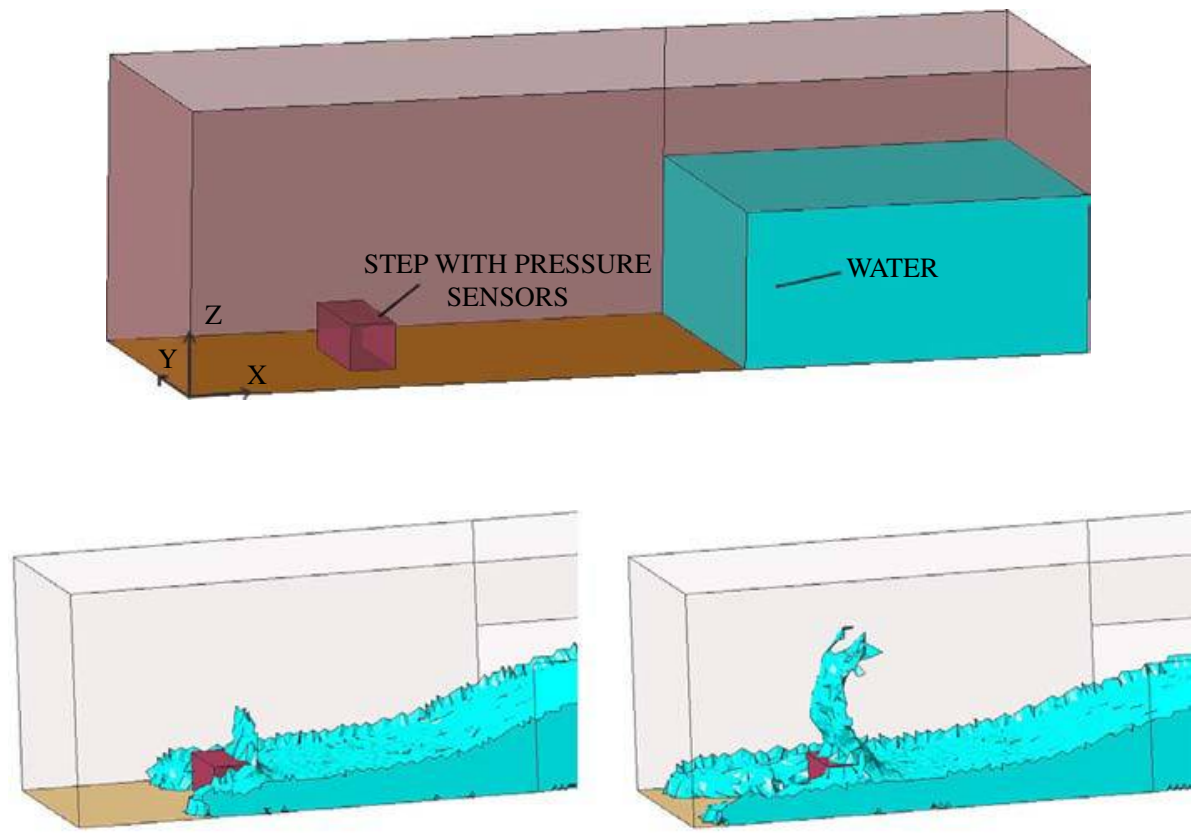

Figure 45.

3D dambreak. PFEM results for the impact of the water over the step
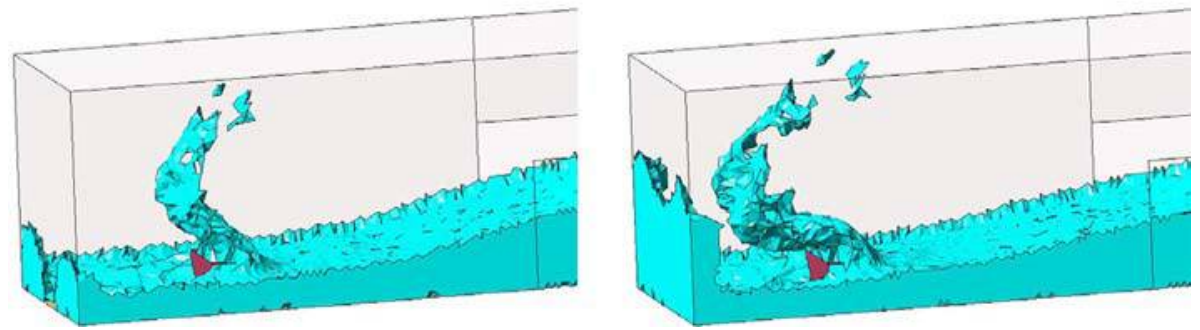

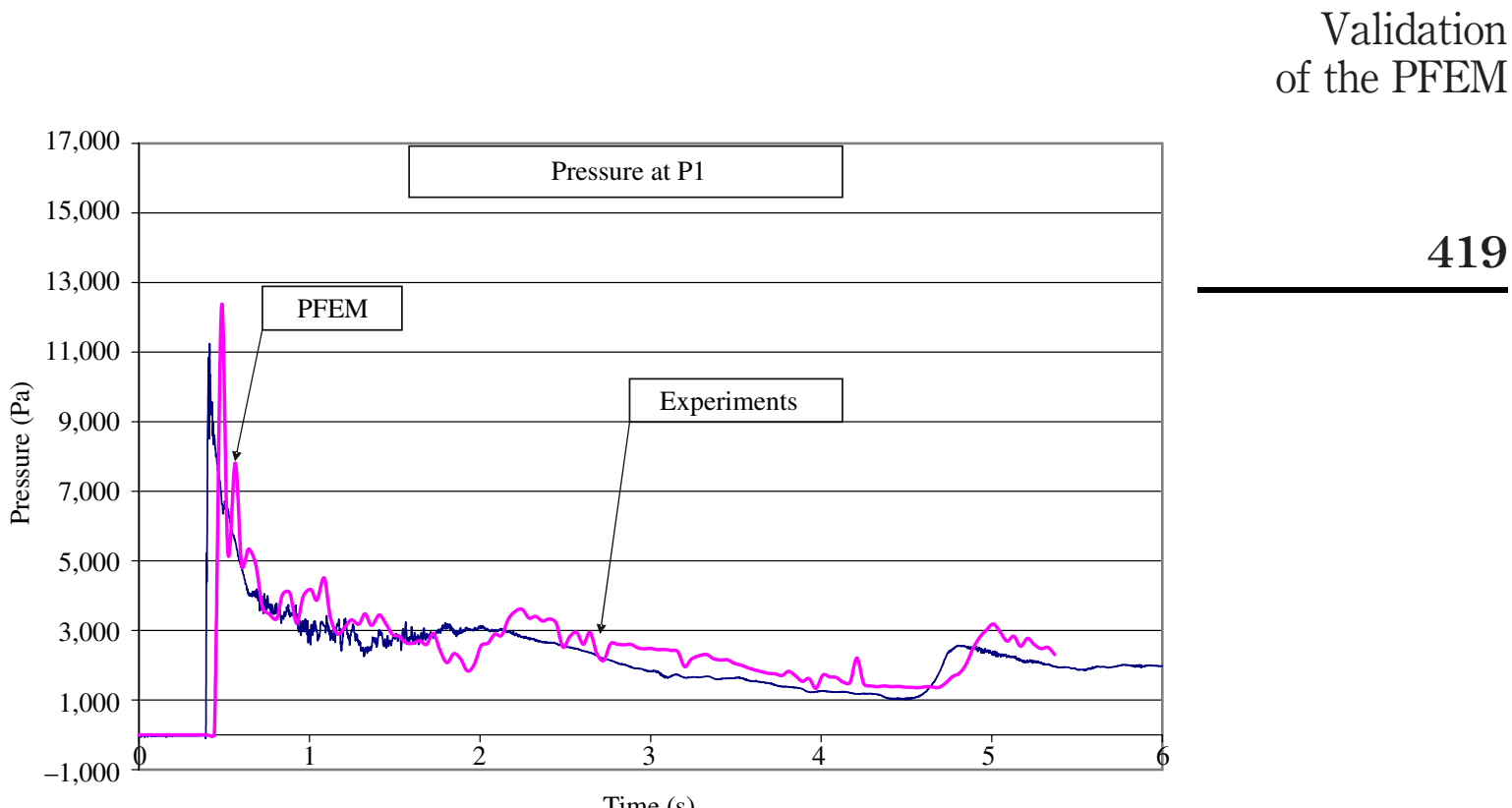

419

(a)

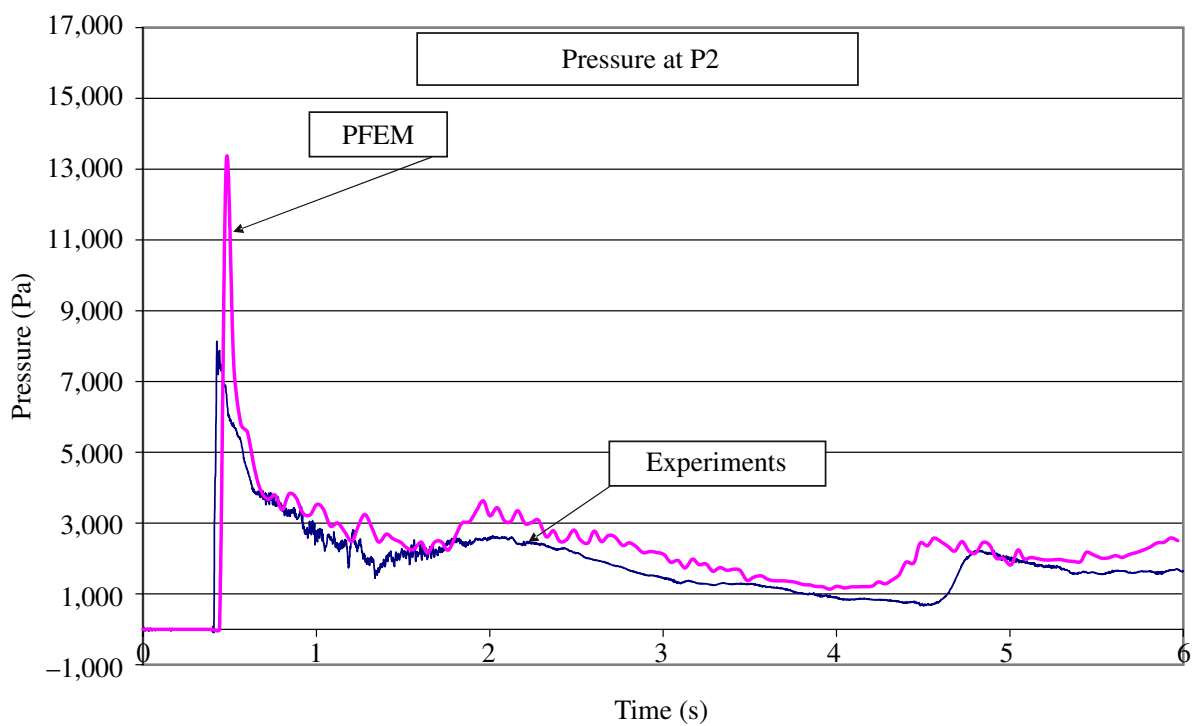

(b)

Figure 46.

3D dambreak. Pressure evolution at points $\mathrm{P} 1$ and P2 of the step 
EC

25,4

420

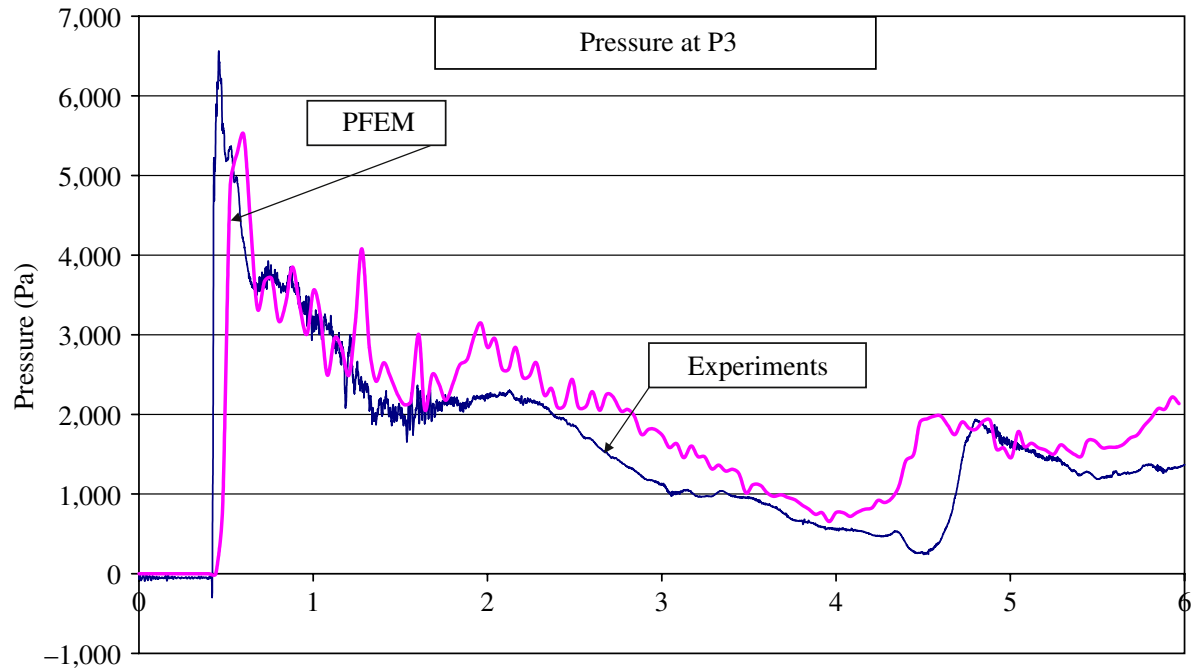

Time (s)

(a)

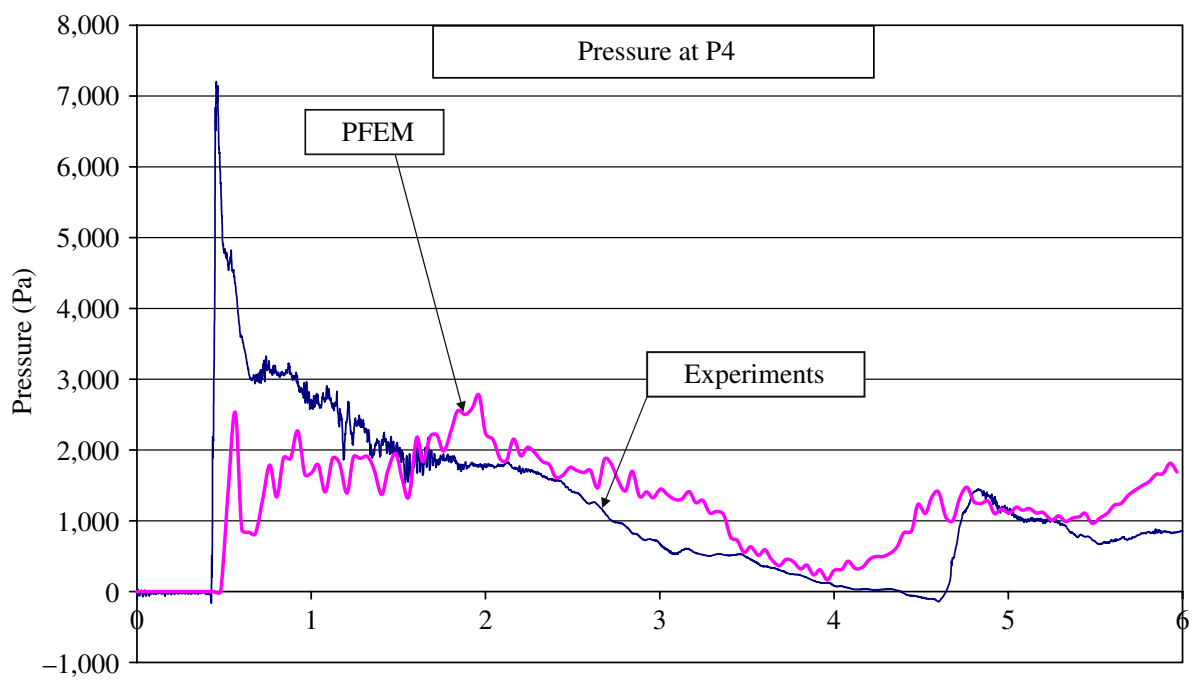

Time (s)

(b)

Figure 47.

3D dambreak. Pressure evolution at points P3 and $\mathrm{P} 4$ of the step 


\section{Validation of the PFEM}

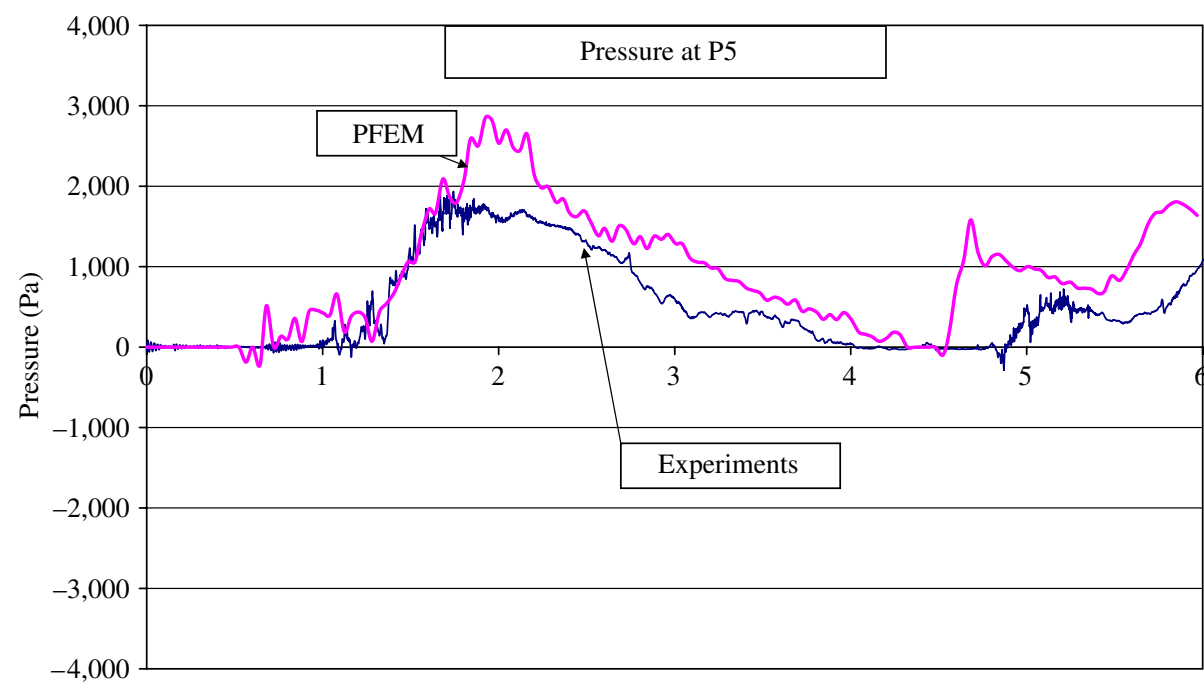

421

Time (s)

(a)

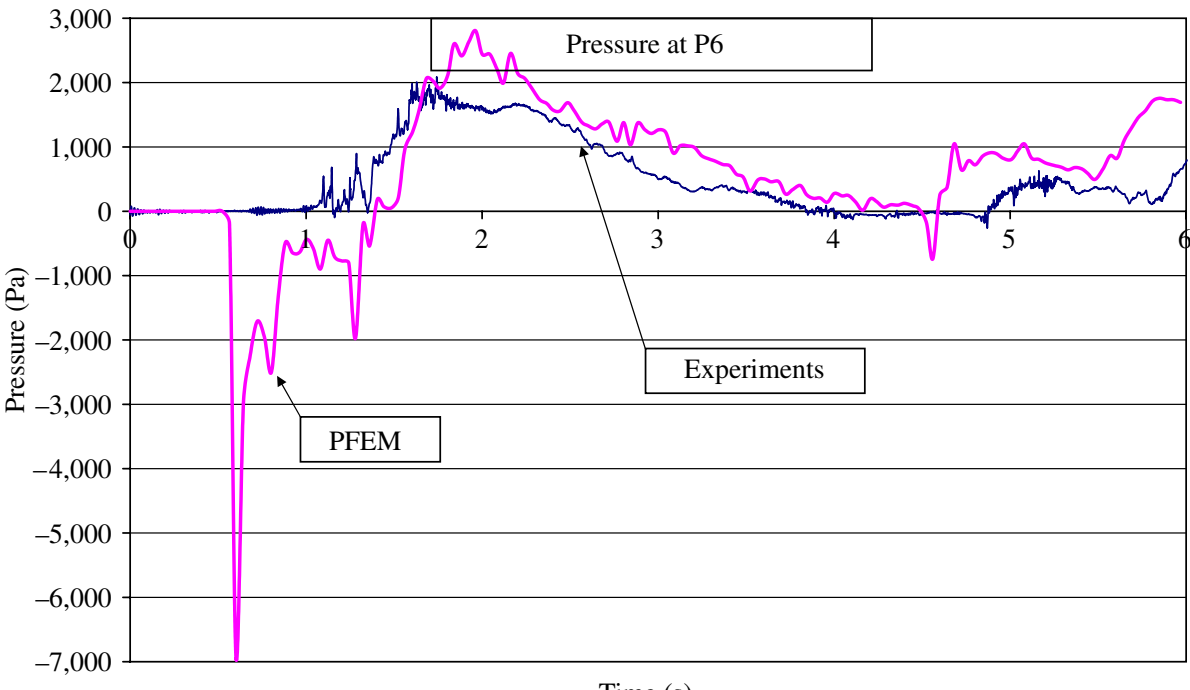

Time (s)

(b)

Figure 48.

3D dambreak. Pressure evolution at points P5 and P6 of the step 
EC

25,4

422

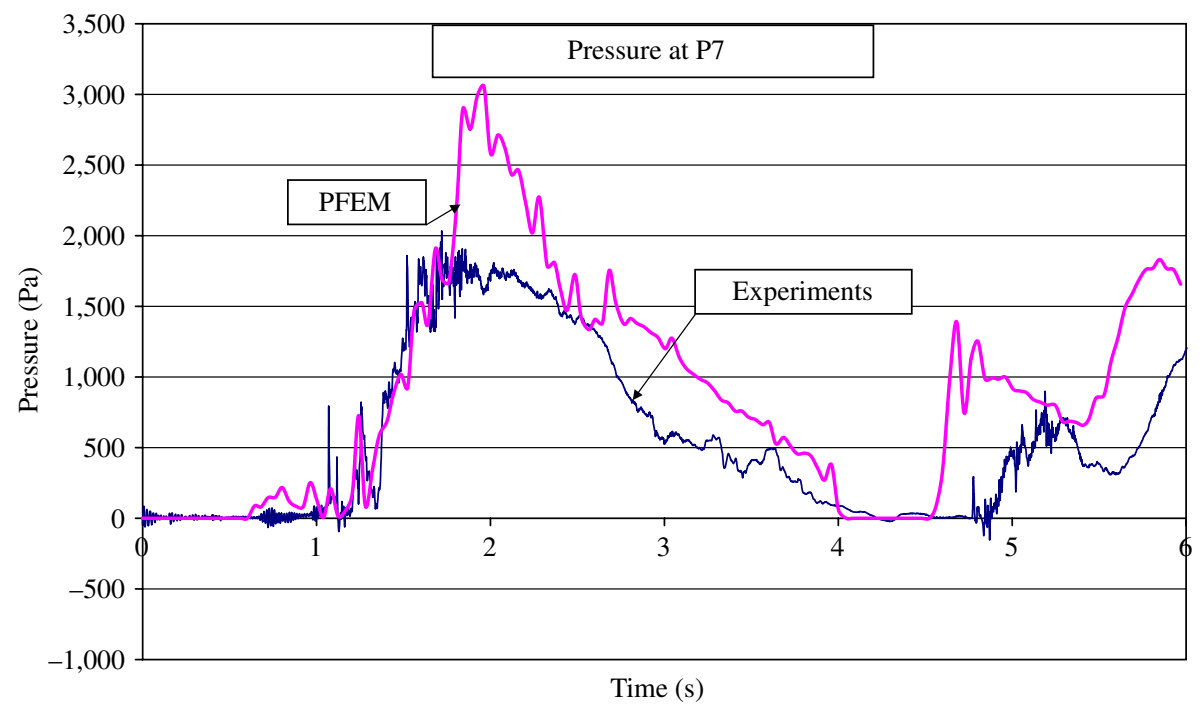

(a)

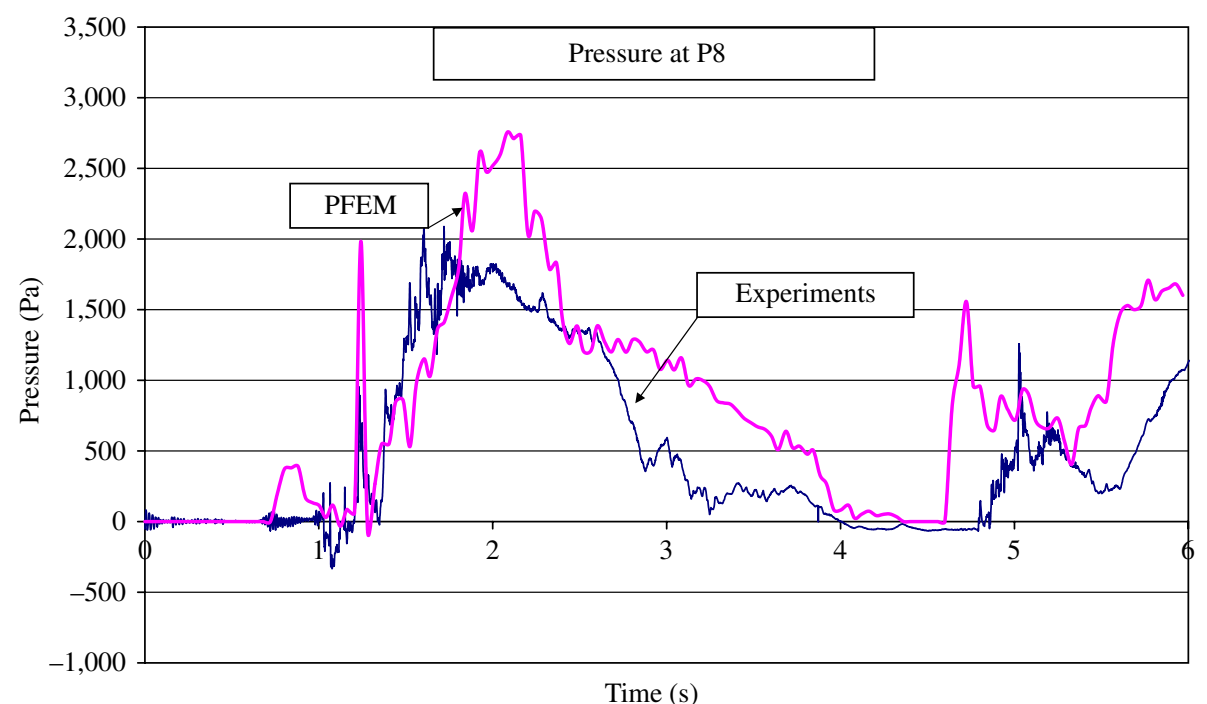

(b)

Figure 49.

3D dambreak. Pressure evolution at points $\mathrm{P} 7$ and P8 of the step 


\section{Validation of the PFEM}

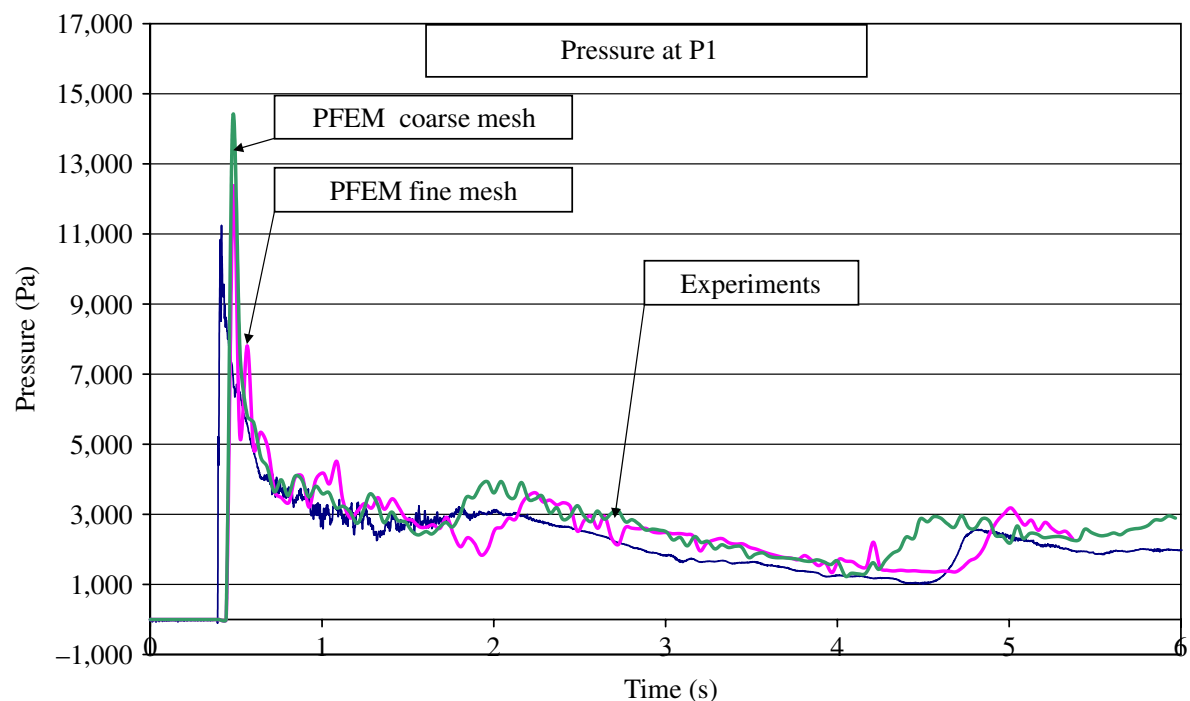

(a)

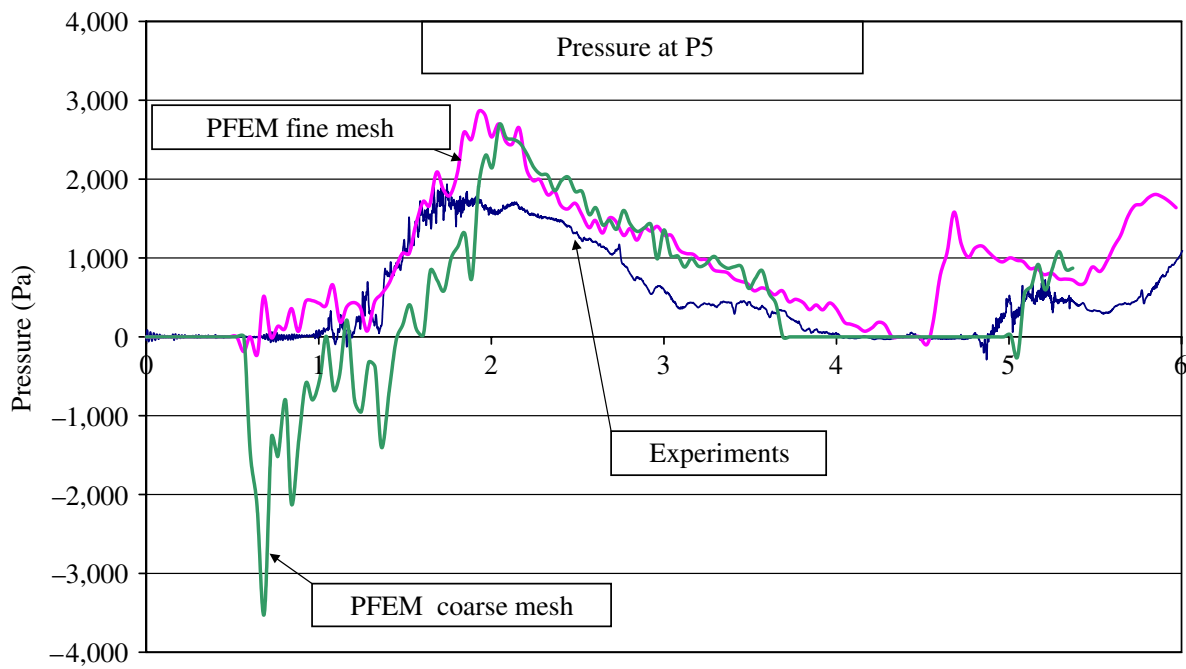

Time (s)

(b)
Figure 50. 3D dambreak. Pressure evolution at P1 and P5. Experimental data compared with PFEM results for two different meshes 
EC

25,4

424

\section{Conclusions}

The PFEM is a powerful tool for solving free surface flows problems involving large deformation of the fluid domain.

Very good results have been obtained for the main flow parameters of relevance for each problem analyzed (such as the velocity field, the pressure distribution and the free surface position) as shown in the comparison with experimental data.

As expected, the mesh size is an important factor which influences the accuracy of the results. For instance, the mesh used in the examples presented is in all cases to coarse for capturing the real development of the viscous boundary layer.

Accurate solutions of the problems analyzed show the ability of the PFEM for reproducing very complex free surface flows to a high level of reliability.

\section{References}

1st Spheric Workshop (2006), "1st SPHERIC workshop: identifying goals and problems in SPH for practical applications in CFD”, available at: http://w3.uniroma1.it/cmar/SPHERIC/ SPHERICWorkshop.htm

Aubry, R., Idelsohn, S.R. and Oñate, E. (2005), "Particle finite element method in fluid mechanics including thermal convection-diffusion”, Computer and Structures, Vol. 83, pp. 1459-75.

Bonet, J., Kulasegaram, S., Rodriguez-Paz, M. and Profit, M. (2006), "Variational formulation for the smooth particle hydrodynamics (SPH) simulation of fluid and solid problems", Computational Methods in Applied Mechanics and Engineering, Vol. 193, pp. 1245-56.

Brownlee, R., Houston, P., Levesley, J. and Rosswog, S. (2007), Algorithms for Approximation, Springer, Berlin.

Cola, R. (2002), Idraulica, IMAGE, Hydraulic Department of the University of Civil Engineering of Padua, Padua.

Dilts, G. (1999), "Moving-least-squares-particle hydrodynamics - I. consistency and stability”, International Journal for Numerical Methods in Engineering, Vol. 44, pp. 1115-55.

Donea, J. and Huerta, A. (2003), Finite Elements Methods for Flow Problems, Wiley, New York, NY.

Edelsbruner, H. and Mücke, E.P. (1994), "Three dimensional alpha shape", ACM Transaction on Graphics, Vol. 13, pp. 43-72.

Ghetti, A. (1984), Idraulica, Cortina, Padua.

GiD (2006), "The personal pre and post processor", The International Center for Numerical Methods in Engineering, available at: http://gid.cimne.upc.es

Heller, V. and Hager, W.H. (2005), "Ski jump hydraulics", Journal of Hydraulic Engineering, Vol. 131, pp. 347-55.

Idelsohn, S.R., Oñate, E. and Del Pin, F. (2004), "The particle finite element method: a powerful tool to solve incompressible flows with free-surfaces and breaking waves", International Journal for Numerical Methods in Engineering, Vol. 61, pp. 964-84.

Idelsohn, S.R., Oñate, E., Del Pin, F. and Calvo, N. (2006), "Fluid-structure interaction using the particle finite element method", Computer Methods in Applied Mechanics and Engineering, Vol. 195, pp. 2100-23.

Juon, R. and Hager, W. (2000), "Flip bucket without and with deflector", Journal of Hydraulic Engineering, Vol. 126, pp. 837-45.

Kleefsman, K.M.T., Fekken, G., Veldman, A., Iwanowski, B. and Buchner, B. (2005), “A volume of fluid based simulation method for wave impact problems”, Journal of Computational Physics, Vol. 206, pp. 363-93. 
Koshizuka, S., Tamako, H. and Oka, Y. (1995), "A particle method for incompressible viscous flow with fluid framentation”, Computational Fluid Dynamic Journal, Vol. 4, pp. $29-46$.

Li, S. and Liu, W. (2002), "Meshfree and particle methods and their applications", Applied Mechanical Review, Vol. 55 No. 1.

Oñate, E. (2000), “A stabilized finite element method for incompressible viscous flows using a finite increment calculus formulation”, Computer Methods in Applied Mechanics and Engineering, Vol. 182 Nos 3/4, pp. 355-70.

Oñate, E. and García, J. (2001), "A finite element method for fluid structure interaction with surface waves using a finite calculus formulation", Computer Methods in Applied Mechanics and Engineering, Vol. 191, pp. 635-60.

Oñate, E. and Idelsohn, S. (1998), "A mesh free finite point method for advective diffusive transport and fluid flow problem”, Computational Mechanics, Vol. 21, pp. 283-92.

Oñate, E., García, J., Idelsohn, S. and Del Pin, F. (2006), "Finite calculus formulations for finite element analysis of incompressible flows. Eulerian, ALE and Lagrangian approaches", Computer Methods in Applied Mechanics and Engineering, Vol. 195, pp. 3001-37.

Oñate, E., Idelsohn, S.R., Del Pin, F. and Aubry, R. (2004), "The particle finite element method. An overview", International Journal of Computational Methods, Vol. 1 No. 2, pp. 267-307.

Osher, S. and Fedkiw, R. (2001), "Level set methods: an overview and some recent results", Journal of Computational Physics, Vol. 169, pp. 463-502.

Osher, S. and Fedkiw, R. (2003), "Level set methods and dynamic implicit surfaces", Computers \& Mathematics with Applications, Vol. 46, pp. 983-4.

Roubtsova, V. and Kahawita, R. (2006), "The SPH technique applied to free-surface flows", Computers \& Fluids, Vol. 35, pp. 1359-71.

Zienkiewicz, O.C., Taylor, R. and Nithiarasu, P. (2005), The Finite Element Method, Vol. 3, Fluid Dynamics, Elsevier.

\section{Corresponding author}

A. Larese can be contacted at: antoldt@cimne.upc.edu

To purchase reprints of this article please e-mail: reprints@emeraldinsight.com Or visit our web site for further details: www.emeraldinsight.com/reprints 


\section{This article has been cited by:}

1. Jai Manik, Amaresh Dalal, Ganesh Natarajan. 2018. A generic algorithm for three-dimensional multiphase flows on unstructured meshes. International Journal of Multiphase Flow 106, 228-242. [Crossref]

2. Ilaria Iaconeta, Antonia Larese, Riccardo Rossi, Zhiming Guo. 2017. Comparison of a Material Point Method and a Galerkin Meshfree Method for the Simulation of Cohesive-Frictional Materials. Materials 10:10, 1150. [Crossref]

3. A. Larese. 2017. A Lagrangian PFEM approach for non-Newtonian viscoplastic materials. Revista Internacional de Métodos Numéricos para Cálculo y Diseño en Ingeniería 33:3-4, 307-317. [Crossref]

4. Fernando Salazar, Javier San-Mauro, Miguel Ángel Celigueta, Eugenio Oñate. 2017. Air demand estimation in bottom outlets with the particle finite element method. Computational Particle Mechanics 4:3, 345-356. [Crossref]

5. Alessandro Franci, Massimiliano Cremonesi. 2017. On the effect of standard PFEM remeshing on volume conservation in free-surface fluid flow problems. Computational Particle Mechanics 4:3, 331-343. [Crossref]

6. GhasemiAmirmahdi, Amirmahdi Ghasemi, NikbakhtiR., R. Nikbakhti, GhasemiAmirreza, Amirreza Ghasemi, HedayatiFaraz, Faraz Hedayati, MalvandiAmir, Amir Malvandi. 2017. Parallelized numerical modeling of the interaction of a solid object with immiscible incompressible two-phase fluid flow. Engineering Computations 34:3, 709-724. [Abstract] [Full Text] [PDF]

7. Alessandro Franci. Unified Stabilized Formulation for Quasi-incompressible Materials 63-145. [Crossref]

8. Alessandro Franci. Introduction 1-16. [Crossref]

9. Van-Tu Nguyen, Warn-Gyu Park. 2016. A free surface flow solver for complex three-dimensional water impact problems based on the VOF method. International Journal for Numerical Methods in Fluids 82:1, 3-34. [Crossref]

10. Amir Malvandi, Amirmahdi Ghasemi, Rasoul Nikbakhti, Amirreza Ghasemi, Faraz Hedayati. 2016. Modeling and parallel computation of the non-linear interaction of rigid bodies with incompressible multiphase flow. Computers \& Mathematics with Applications 72:4, 1055-1065. [Crossref]

11. F. Salazar, J. Irazábal, A. Larese, E. Oñate. 2016. Numerical modelling of landslide-generated waves with the particle finite element method (PFEM) and a non-Newtonian flow model. International Journal for Numerical and Analytical Methods in Geomechanics 40:6, 809-826. [Crossref]

12. Juan M. Gimenez, Pedro Morin, Norberto Nigro, Sergio Idelsohn. Numerical Comparison of the Particle Finite Element Method Against an Eulerian Formulation 7-24. [Crossref]

13. Alessandro Franci, Eugenio Oñate, Josep Maria Carbonell. 2016. Unified Lagrangian formulation for solid and fluid mechanics and FSI problems. Computer Methods in Applied Mechanics and Engineering 298, 520-547. [Crossref]

14. Zhe Sun, K. Djidjeli, Jing T. Xing, Fai cheng. 2015. Modified MPS method for the 2D fluid structure interaction problem with free surface. Computers \& Fluids 122, 47-65. [Crossref]

15. Antonia Larese, Riccardo Rossi, Eugenio Oñate, Miguel Ángel Toledo, Rafael Morán, Hibber Campos. 2015. Numerical and Experimental Study of Overtopping and Failure of Rockfill Dams. International Journal of Geomechanics 15:4, 04014060. [Crossref]

16. Sergio Idelsohn, Eugenio Oñate, Norberto Nigro, Pablo Becker, Juan Gimenez. 2015. Lagrangian versus Eulerian integration errors. Computer Methods in Applied Mechanics and Engineering 293, 191-206. [Crossref] 
17. Yexiang Xiao, Zhengwei Wang, Jidi Zeng, jintai Zheng, Jiayang Lin, Lanjin Zhang. 2015. Prototype and numerical studies of interference characteristics of two ski-jump jets from opening spillway gates. Engineering Computations 32:2, 289-307. [Abstract] [Full Text] [PDF]

18. Alessandro Franci, Eugenio Oñate, Josep Maria Carbonell. 2015. On the effect of the bulk tangent matrix in partitioned solution schemes for nearly incompressible fluids. International Journal for Numerical Methods in Engineering 102:3-4, 257-277. [Crossref]

19. Francisco Caballero, Fernando Salazar, Javier Mauro, Miguel Toledo. Physical and numerical modeling for understanding the hydraulic behaviour of Wedge-Shaped-Blocks spillways 193-203. [Crossref]

20. Thai Son Dang, Günther Meschke. 2014. An ALE-PFEM method for the numerical simulation of twophase mixture flow. Computer Methods in Applied Mechanics and Engineering 278, 599-620. [Crossref]

21. Sergio R. Idelsohn, Julio Marti, Pablo Becker, Eugenio Oñate. 2014. Analysis of multifluid flows with large time steps using the particle finite element method. International Journal for Numerical Methods in Fluids 75:9, 621-644. [Crossref]

22. Eugenio Oñate, Alessandro Franci, Josep M. Carbonell. 2014. A particle finite element method for analysis of industrial forming processes. Computational Mechanics 54:1, 85-107. [Crossref]

23. Juan M. Gimenez, Norberto M. Nigro, Sergio R. Idelsohn. 2014. Evaluating the performance of the particle finite element method in parallel architectures. Computational Particle Mechanics 1:1, 103-116. [Crossref]

24. Eugenio Oñate, Miguel Angel Celigueta, Salvador Latorre, Guillermo Casas, Riccardo Rossi, Jerzy Rojek. 2014. Lagrangian analysis of multiscale particulate flows with the particle finite element method. Computational Particle Mechanics 1:1, 85-102. [Crossref]

25. Eugenio Oñate, Alessandro Franci, Josep M. Carbonell. 2014. Lagrangian formulation for finite element analysis of quasi-incompressible fluids with reduced mass losses. International Journal for Numerical Methods in Fluids 74:10, 699-731. [Crossref]

26. D. Pozo, F. Salazar, M.Á. Toledo. 2014. Modelación del funcionamiento hidráulico de los dispositivos de aireación de desagües de fondo de presas mediante el método de partículas y elementos finitos. Revista Internacional de Métodos Numéricos para Cálculo y Diseño en Ingeniería 30:1, 51-59. [Crossref]

27. Michael Dumbser, Walter Boscheri. 2013. High-order unstructured Lagrangian one-step WENO finite volume schemes for non-conservative hyperbolic systems: Applications to compressible multi-phase flows. Computers \& Fluids 86, 405-432. [Crossref]

28. L. Sun, G.F. Zhao, J. Zhao. 2013. Particle manifold method (PMM): A new continuum-discontinuum numerical model for geomechanics. International Journal for Numerical and Analytical Methods in Geomechanics 37:12, 1711-1736. [Crossref]

29. P. Ryzhakov, R. Rossi, A. Viña, E. Oñate. 2013. Modelling and simulation of the sea-landing of aerial vehicles using the Particle Finite Element Method. Ocean Engineering 66, 92-100. [Crossref]

30. Fernando Salazar, Rafael Morán, Riccardo Rossi, Eugenio Oñate. 2013. Analysis of the discharge capacity of radial-gated spillways using CFD and ANN - Oliana Dam case study. Journal of Hydraulic Research 51:3, 244-252. [Crossref]

31. Michael Dumbser. 2013. A diffuse interface method for complex three-dimensional free surface flows. Computer Methods in Applied Mechanics and Engineering 257, 47-64. [Crossref]

32. R. Rossi, A. Larese, P. Dadvand, E. Oñate. 2013. An efficient edge-based level set finite element method for free surface flow problems. International Journal for Numerical Methods in Fluids 71:6, 687-716. [Crossref] 
33. Sergio Rodolfo Idelsohn, Norberto Marcelo Nigro, Juan Marcelo Gimenez, Riccardo Rossi, Julio Marcelo Marti. 2013. A fast and accurate method to solve the incompressible Navier-Stokes equations. Engineering Computations 30:2, 197-222. [Abstract] [Full Text] [PDF]

34. A. Larese, R. Rossi, E. Oñate, S. R. Idelsohn. 2012. A coupled PFEM-Eulerian approach for the solution of porous FSI problems. Computational Mechanics 50:6, 805-819. [Crossref]

35. M. Mier-Torrecilla, A. Geyer, J. C. Phillips, S. R. Idelsohn, E. Oñate. 2012. Numerical simulations of negatively buoyant jets in an immiscible fluid using the Particle Finite Element Method. International Journal for Numerical Methods in Fluids 69:5, 1016-1030. [Crossref]

36. F. Salazar, E. Oñate, R. Morán. 2012. Modelación numérica de deslizamientos de ladera en embalses mediante el Método de Partículas y Elementos Finitos (PFEM). Revista Internacional de Métodos Numéricos para Cálculo y Diseño en Ingeniería 28:2, 112-123. [Crossref]

37. F. Mossaiby, R. Rossi, P. Dadvand, S. Idelsohn. 2012. OpenCL-based implementation of an unstructured edge-based finite element convection-diffusion solver on graphics hardware. International Journal for Numerical Methods in Engineering 89:13, 1635-1651. [Crossref]

38. C. G. Koh, M. Gao, C. Luo. 2012. A new particle method for simulation of incompressible free surface flow problems. International Journal for Numerical Methods in Engineering 89:12, 1582-1604. [Crossref]

39. F Salazar, E Oñate, R Morán. Numerical modeling of landslides in reservoirs using the Particle Finite Element Method (PFEM) 245-250. [Crossref]

40. Eugenio Oñate, Miguel Angel Celigueta, Sergio R. Idelsohn, Fernando Salazar, Benjamín Suárez. 2011. Possibilities of the particle finite element method for fluid-soil-structure interaction problems. Computational Mechanics 48:3, 307-318. [Crossref]

41. M. Cremonesi, A. Frangi, U. Perego. 2011. A Lagrangian finite element approach for the simulation of water-waves induced by landslides. Computers \& Structures 89:11-12, 1086-1093. [Crossref]

42. M. Cremonesi, L. Ferrara, A. Frangi, U. Perego. 2010. Simulation of the flow of fresh cement suspensions by a Lagrangian finite element approach. Journal of Non-Newtonian Fluid Mechanics 165:23-24, 1555-1563. [Crossref]

43. . Outlet works 451-624. [Crossref]

44. P. B. Ryzhakov, R. Rossi, S. R. Idelsohn, E. Oñate. 2010. A monolithic Lagrangian approach for fluidstructure interaction problems. Computational Mechanics 46:6, 883-899. [Crossref]

45. Pooyan Dadvand, Riccardo Rossi, Eugenio Oñate. 2010. An Object-oriented Environment for Developing Finite Element Codes for Multi-disciplinary Applications. Archives of Computational Methods in Engineering 17:3, 253-297. [Crossref]

46. Erb F. Lins, Renato N. Elias, Fernando A. Rochinha, Alvaro L. G. A. Coutinho. 2010. Residual-based variational multiscale simulation of free surface flows. Computational Mechanics 46:4, 545-557. [Crossref]

47. M. Cremonesi, A. Frangi, U. Perego. 2010. A Lagrangian finite element approach for the analysis of fluid-structure interaction problems. International Journal for Numerical Methods in Engineering n/a-n/ a. [Crossref]

48. Sergio Idelsohn, Monica Mier-Torrecilla, Eugenio Oñate. 2009. Multi-fluid flows with the Particle Finite Element Method. Computer Methods in Applied Mechanics and Engineering 198:33-36, 2750-2767. [Crossref]

49. Julio Garcia-Espinosa, Aleix Valls, Eugenio Oñate. 2008. ODDLS: A new unstructured mesh finite element method for the analysis of free surface flow problems. International Journal for Numerical Methods in Engineering 76:9, 1297-1327. [Crossref] 